\title{
CrystEngComm
}

Check for updates

Cite this: CrystEngComm, 2019, 21, 77

Received 30th October 2018 ,

Accepted 3rd December 2018

DOI: $10.1039 / c 8 c e 01860$

rsc.li/crystengcomm

\section{New rhenium-tricarbonyl complexes bearing halogen-substituted bidentate ligands: structural, computational and Hirshfeld surfaces studies $\dagger+$}

\author{
Reza Kia, (D)*a Soheil Mahmoudi a and Paul R. Raithby (iD ${ }^{\mathrm{b}}$
}

\begin{abstract}
A series of ten rhenium tricarbonyl complexes (C1-C10), bearing halogen-substituted bidentate N,N-donor ligands with halogens or trifluoromethyl groups $\left(\mathrm{X}=-\mathrm{F},-\mathrm{Cl},-\mathrm{Br}\right.$, and $\left.-\mathrm{CF}_{3}\right)$ in different positions on the aromatic rings were synthesized and characterized by FT-IR and ${ }^{1} \mathrm{H}-\mathrm{NMR}$ spectroscopy and their solid-state structures were determined by single crystal $\mathrm{X}$-ray diffraction. The resultant complexes $\operatorname{Re}(\mathrm{CO})_{3}(\mathrm{~N}, \mathrm{~N}) \mathrm{X}$ display an octahedral coordination geometry around the central Re atom, and in all the complexes the $\operatorname{Re}(\mathrm{CO})_{3}$ unit adopts a fac geometry. The metal-bound halogen atoms along with the halogen-substituted ligands were used to fine-tune the electron density of the halogen $\sigma$-hole on the coordinated halide that is involved in halogen-halogen and other intermolecular interactions. This series of compounds was used to explore the range of possible intermolecular interactions involving rhenium coordinated halides. These supramolecular interactions include: (i) halogen bonding through the metal-bound halogen with the carbonbound halogen $(\operatorname{Re}-\mathrm{X} \cdots \mathrm{X}-\mathrm{C}$ ), (ii) halogen bonding through the carbon-bound halogen with another carbon-bound halogen $(\mathrm{C}-\mathrm{X} \cdots \mathrm{X}-\mathrm{C})$, (iii) dipolar interactions through carbonyl-carbonyl (CO $\cdots \mathrm{CO}$ ), (iv) $\mathrm{C}$ $\mathrm{H} \cdots \mathrm{X}$ hydrogen bonding interactions, (v) $\mathrm{C}-\mathrm{H} \cdots \mathrm{O}$ hydrogen bonding interactions, (vi) halogen $(\mathrm{X}) \cdots$ heteroatom $(\mathrm{N}, \mathrm{O})$ interactions and (vii) metal-bond carbonyl lone pair with aromatic $\pi$-ring interaction, Re$\mathrm{CO}$ (lone pair) $\cdots \pi$ (aromatic ring). In each case the molecular electrostatic potential and non-covalent interaction index were calculated. Crystal packing analyses using Hirshfeld surface calculation confirmed that metal-bound halogen is more effective than carbon-bound halogen in the formation of intermolecular interactions. Complexes $\mathrm{C} 8$ and $\mathrm{C} 10$ featured interesting intramolecular Re-CO(lone pair) $\cdots \pi$ interactions, the presence of which were confirmed by molecular orbital and non-covalent interaction index ( $\mathrm{NCl}$ ) calculations.
\end{abstract}

\section{Introduction}

The assembly of molecular complexes in the solid-state to form supramolecular arrays is governed by a range of competing non-covalent interactions, and the structures of the resultant assemblies are based on the directionality, strength and specificity of the interactions involved. ${ }^{1,2}$ As such, the structural importance of non-covalent interactions has attracted extensive interest in the areas of crystal engineering, ${ }^{3}$ molecular recognition, ${ }^{4}$ protein folding, ${ }^{5}$ enzymatic reactions, ${ }^{5}$ supra-

\footnotetext{
${ }^{a}$ Chemistry Department, Sharif University of Technology, P.O. Box 11155-3516, Tehran, Iran.E-mail: rkia@sharif.edu, zsrkk@yahoo.com; Tel: +98 2166165332 ${ }^{b}$ Department of Chemistry, University of Bath, Claverton Down, Bath, BA2 7AY, $U K$

$\dagger$ Electronic supplementary information (ESI) available. CCDC 1871495-1871503. For ESI and crystallographic data in CIF or other electronic format see DOI: 10.1039/c8ce01860j

$\$$ This paper is dedicated to the memory of Dr Frank H. Allen, a mentor, friend and one of the pioneers of the study of intermolecular interactions in the solidstate.
}

molecular chemistry ${ }^{6}$ and crystal structure prediction. ${ }^{7}$ The competition between different types of non-covalent interactions in the solid-state and knowledge of the strengths of such interactions is at the heart of crystal engineering. ${ }^{8}$ The competition or cooperative behavior between hydrogen bonds and halogen bonds in the solid-state has been studied in various systems. ${ }^{9}$ Among the different non-H-bond mediated non-covalent interactions which have received extensive attention is halogen bonding. It is clearly defined as a noncovalent interaction between an electron deficient halogen atom and an electron donor halogen. ${ }^{10-12}$

Politzer et al. showed the existence of an electropositive crown so-called " $\sigma$-hole" - a zone of low electron density displaying a positive electrostatic potential of the halogen atom directed to the electron donor. ${ }^{13,14}$ On the other hand, it has been shown that the halogen bonding is not merely electrostatic in nature but the contributing factors are a convolution of electrostatic, ${ }^{14}$ polarization, ${ }^{15}$ charge transfer $^{16}$ and dispersion ${ }^{17,18}$ forces and the contribution of each of these factors is directly affected by the molecular components 
involved in the interactions. The extensive studies by Metrangolo, Resnati, and Brammer and coworkers have revolutionized the conception of halogen bonding and made it applicable in different areas of chemistry in which molecular recognition plays a central role. ${ }^{19-23}$

Most of the studies were based on the halogen interactions in organic systems but the seminal work by Brammer and co-workers systematically examined the potential of metal-bound halogens such as the halometallate anion (M-X) with halocarbon (C-X) groups for halogen bonding. ${ }^{24-26}$ From large numbers of crystallographic observations, it has been substantiated that the metal-bound halogens and halide anions are strongly nucleophilic compared to carbon-bound halogens which have only a very weakly nucleophilic character in hydrogen bonding interactions, establishing a hierarchy of hydrogen bond strengths as $\mathrm{D}-\mathrm{H} \cdots \mathrm{X}^{-}>\mathrm{D}-\mathrm{H} \cdots \mathrm{X}-\mathrm{M} \gg$ $\mathrm{D}-\mathrm{H} \cdots \mathrm{X}-\mathrm{C}(\mathrm{D}=\mathrm{N}, \mathrm{O}, \mathrm{C}) .^{20,24}$ This can also be extended to halogen bonding interactions between $\mathrm{M}-\mathrm{X}^{\prime}$ and $\mathrm{C}-\mathrm{X}\left(\mathrm{M}-\mathrm{X}^{\prime}\right.$ $\cdots \mathrm{X}-\mathrm{C}$ in which $\mathrm{X}^{\prime}=\mathrm{X}$ or $\mathrm{X}^{\prime} \neq \mathrm{X}$ ) since a study was performed using metal-organic tectons which bring coordination bonds into competition with directional intermolecular noncovalent interactions. ${ }^{27}$

Additionally, non-covalent interactions involving $\pi$-systems such as $\pi$ (aromatic) $\cdots \operatorname{lp}$ (lone pair), have been extensively studied in recent decades. Originally, the existence of such interaction was studied in biological systems and it has been shown that such interactions are of great importance in the structures of biological macromolecules. ${ }^{28}$ To this effect, the $1 \mathrm{l} \cdots \pi$ interaction involving the carbonyl group is of considerable interest in metal carbonyl complexes recently and it has been found that some metal-carbonyl complexes feature interesting intraand/or intermolecular $\mathbf{M}-\mathrm{CO}$ (lone pair) $\cdots \pi$ (arene) interactions. $^{29,30}$ The $\pi$-systems involved are usually $\pi$-acidic aromatic rings with electron-withdrawing halo-, nitro- and cyanofunctional groups or electron-deficient aromatic heterocycles. ${ }^{31}$

Another interesting intra- and intermolecular interaction is the $\mathrm{n} \rightarrow \pi^{*}$ interaction which has been extensively studied in biomolecules. Such an interaction was reported for the first time very recently by Echeverria $^{32}$ and Mooibroek et al. ${ }^{33}$ in transition metal complexes containing carbonyl ligands which surprisingly stabilize precise molecular conformations due to the overlap between donor and acceptor complexes. The ground work of such interaction in organic carbonyl compounds was investigated by Burgi and Dunitz in 1975. ${ }^{34}$

Herein, we report the design, synthesis, characterization, structural chemistry and theoretical calculations of a series of new chloro- and bromo-rhenium(I) tricarbonyl complexes bearing halogen and/or trifluoromethyl substituted N,N-donor ligands. We chose the complexes containing the ubiquitous " $\mathrm{Re}(\mathrm{CO})_{3} \mathrm{X}$ " fragment because of the rich redox and luminescent properties that these complexes possess, ${ }^{35}$ and because of the diverse structural chemistry that they exhibit. ${ }^{36}$ The strategy behind this design was to facilitate the possibility of different intermolecular interactions between the ranges of functional groups in these complexes.

\section{Experimental}

\section{General}

All chemicals used were analytical reagent grade. All solvents purchased from Merck were reagent grade and purified by standard techniques where required. Commercially available $\mathrm{Re}(\mathrm{CO})_{5} \mathrm{Cl}$ and $\operatorname{Re}(\mathrm{CO})_{5} \mathrm{Br}$ were obtained from Aldrich and were used as received. The ${ }^{1} \mathrm{H}-\mathrm{NMR}$ spectra (Fig. S1-S8, ESI $\dagger$ ), were recorded using BRUKER AVANCE $500 \mathrm{MHz}$ spectrometer in $\mathrm{CDCl}_{3}$. FT-IR spectra (Fig. S9-S16 $\dagger$ ) in the region of $4000-400 \mathrm{~cm}^{-1}$ were recorded in $\mathrm{KBr}$ pellets with a Shimadzu IR Prestige-21 FTIR spectrophotometer. The elemental analyses were performed using a LECO CHN instrument. The syntheses and crystal structures of the halogensubstituted bidentate N,N-ligands (Scheme 1) and the 32ClFenReBr complex (abbreviated as C1), have been reported previously. ${ }^{37-42}$ The preparation of all of the $\operatorname{Re}(\mathrm{I})$ tricarbonyl complexes has been achieved using literature methods. $^{43}$

\section{Crystallisations}

Crystals were obtained by vapour diffusion of $n$-hexane into the dichloromethane solution of the complexes under ambient conditions.

32ClFenReCl (C2). To a $25 \mathrm{~mL}$ round-bottom flask containing $0.55 \mathrm{mmol}(188 \mathrm{mg})$ of ligand $\mathbf{L 1}$, dissolved in 20 $\mathrm{mL}$ of degassed $\mathrm{CH}_{2} \mathrm{Cl}_{2}$ and toluene $(1: 2)$, was added an equimolar amount of $\mathrm{Re}(\mathrm{CO})_{5} \mathrm{Cl}(0.55 \mathrm{mmol}, 0.20 \mathrm{~g})$. The mixture was heated at reflux for $3 \mathrm{~h}$. The solution was concentrated to $5 \mathrm{~mL}$ and $n$-hexane was added to precipitate the complex quantitatively. Calc.: C, 35.28; H, 1.87; N, 4.33. Found: C, 35.31; H, 1.86; N, 4.35. FTIR (KBr, cm ${ }^{-1}$ ): 2021, 1917 and 1882 $(\mathrm{CO}) ; 1624(\mathrm{C}=\mathrm{N}) .{ }^{1} \mathrm{H}-\mathrm{NMR}\left(\mathrm{CDCl}_{3}, \delta_{\mathrm{ppm}}\right): 4.15-4.35(\mathrm{~m}$, $\mathrm{CH}_{2}$ ); 7.30-8.20 (m, aromatic $\mathrm{H}$ ); 8.90 (s, iminic $\mathrm{H}$ ).

34ClFenReBr (C3). This complex was synthesized by a procedure similar to $\mathrm{C} 2$, but using ligand $\mathrm{L} 2$ and $\operatorname{Re}(\mathrm{CO})_{5} \mathrm{Br}$ (0.55 mmol, 0.22 g). Calc.: C, 35.01; H, 1.75; N, 4.05. Found: C, 34.98; H, 1.77; N, 4.08. FTIR (KBr, $\left.\mathrm{cm}^{-1}\right)$ : 2021, 1901 and $1886(\mathrm{CO}) ; 1627(\mathrm{C}=\mathrm{N}) .{ }^{1} \mathrm{H}-\mathrm{NMR}\left(\mathrm{CDCl}_{3}, \delta_{\mathrm{ppm}}\right): 4.00-4.10(\mathrm{~m}$, $\left.\mathrm{CH}_{2}\right)$; 4.30-4.40 (m, $\left.\mathrm{CH}_{2}\right)$; 7.20-7.30 (m, aromatic H); 7.707.85 (m, aromatic $\mathrm{H})$; 8.75 (s, iminic $\mathrm{H}$ ).

34ClFenReCl (C4). This complex was synthesized by a procedure similar to $\mathbf{C} 2$ but using ligand L2. Calc.: C, 35.28; $\mathrm{H}$, 1.87; N, 4.33. Found: C, 35.27; H, 1.88; N, 4.34. FTIR (KBr, $\left.\mathrm{cm}^{-1}\right): 2021$ and $1890(\mathrm{CO}) ; 1635(\mathrm{C}=\mathrm{N}) .{ }^{1} \mathrm{H}-\mathrm{NMR}\left(\mathrm{CDCl}_{3}\right.$, $\left.\delta_{\text {ppm }}\right)$ : 4.00-4.10 (m, $\left.\mathrm{CH}_{2}\right) ; 4.30-4.40\left(\mathrm{~m}, \mathrm{CH}_{2}\right) ; 7.20-7.30(\mathrm{~m}$, aromatic $\mathrm{H})$; 7.70-7.85 (m, aromatic $\mathrm{H}) ; 8.75$ (s, iminic $\mathrm{H}$ ).

35ClenReBr (C5). This complex was synthesized by a procedure similar to $\mathbf{C} 2$, but using ligand $\mathbf{L 3}(0.55 \mathrm{mmol}, 0.20 \mathrm{~g}$ ) and $\operatorname{Re}(\mathrm{CO})_{5} \mathrm{Br}$ (0.55 mmol, $\left.0.22 \mathrm{~g}\right)$. Calc: C, 31.51; H, 1.67; N, 3.87. Found: C, 31.50; H, 1.68; N, 3.88. FTIR ( $\left.\mathrm{KBr}, \mathrm{cm}^{-1}\right)$ : 2021 and $1898(\mathrm{CO}) ; 1627(\mathrm{C}=\mathrm{N}) .{ }^{1} \mathrm{H}-\mathrm{NMR}\left(\mathrm{CDCl}_{3}, \delta_{\mathrm{ppm}}\right)$ : 4.00-4.15 (m, $\left.\mathrm{CH}_{2}\right)$; 4.35-4.45 (m, $\left.\mathrm{CH}_{2}\right)$; 7.40-7.50 (m, aromatic $\mathrm{H}) ; 7.70-7.80(\mathrm{~m}$, aromatic $\mathrm{H}) ; 8.75$ (s, iminic $\mathrm{H})$.

35ClenReCl (C6). This complex was synthesized by a procedure similar to $\mathrm{C} 2$, but using ligand $\mathrm{L} 3(0.55 \mathrm{mmol}, 0.20 \mathrm{~g})$ 

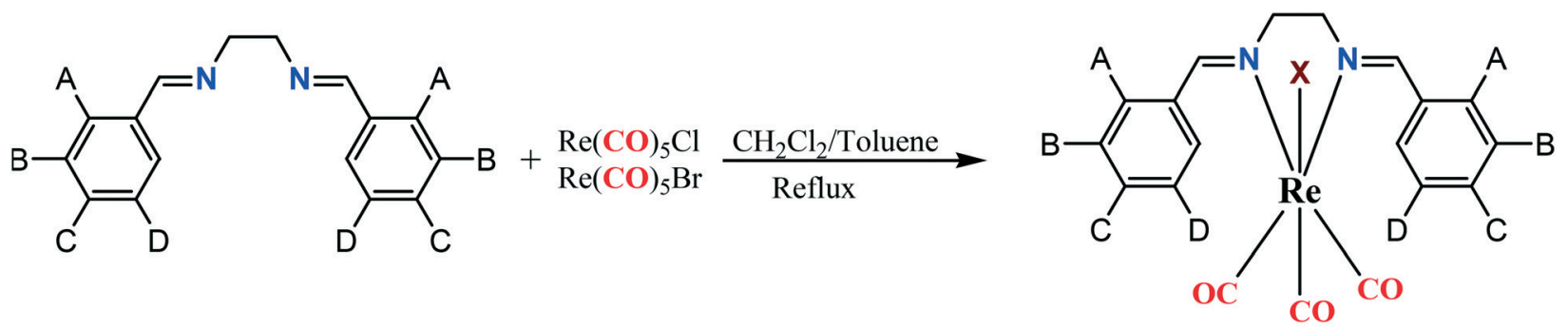

L1: $\mathrm{C}=\mathrm{D}=\mathrm{H}, \mathrm{B}=\mathrm{Cl}, \mathrm{A}=\mathrm{F} ; \mathbf{3 2 C l F e n}$

L2: $\mathrm{A}=\mathrm{D}=\mathrm{H}, \mathrm{B}=\mathrm{Cl}, \mathrm{C}=\mathrm{F}$; 34ClFen

L3: $\mathrm{A}=\mathrm{C}=\mathrm{H}, \mathrm{B}=\mathrm{D}=\mathrm{Cl}$; 35Clen

L4: $\mathrm{B}=\mathrm{D}=\mathrm{H}, \mathrm{A}=\mathrm{F}, \mathrm{C}=\mathrm{Br}, \mathbf{4 2 B r F e n}$

L5: $\mathrm{A}=\mathrm{D}=\mathrm{H}, \mathrm{B}=\mathrm{F}, \mathrm{C}=\mathrm{Cl}$, 43CIFen

L6: $\mathrm{B}=\mathrm{C}=\mathrm{H}, \mathrm{A}=\mathrm{Cl}, \mathrm{D}=\mathrm{CF}_{3}$, CIFen

C1: L1, $X=B r$; 32CIFenReBr

C2: L1, $\mathrm{X}=\mathrm{Cl}$; 32CIFenReCl

C3: L2, $\mathrm{X}=\mathrm{Br}$; 34CIFenReBr

C4: L2, $\mathrm{X}=\mathrm{Cl}, 34 \mathrm{CIFenReCl}$

C5: L3, $\mathrm{X}=\mathrm{Br}$, 35ClenReBr

C6: $\mathrm{L3}, \mathrm{X}=\mathrm{Cl}, \mathbf{3 5 C l e n R e C l}$

C7: L4, $\mathrm{X}=\mathrm{Cl}$, 42BrFenReCl

C8: L5, $\mathrm{X}=\mathrm{Cl}$, 43CIFenReCl

C9: L6, $X=\mathrm{Br}$, CIFenReBr

C10: L6, $\mathrm{X}=\mathrm{Br}$, CIFenReBr'

Scheme 1 Synthesis pathway of C1-C10.

and $\operatorname{Re}(\mathrm{CO})_{5} \mathrm{Cl}(0.55 \mathrm{mmol}, 0.20 \mathrm{~g})$. Calc: $\mathrm{C}, 35.01 ; \mathrm{H}, 1.75 ; \mathrm{N}$, 4.05. Found: $\mathrm{C}, 34.98 ; \mathrm{H}, 1.77 ; \mathrm{N}, 4.08$. FTIR $\left(\mathrm{KBr}, \mathrm{cm}^{-1}\right)$ : 2021 and $1898(\mathrm{CO}) ; 1627(\mathrm{C}=\mathrm{N}) .{ }^{1} \mathrm{H}-\mathrm{NMR}\left(\mathrm{CDCl}_{3}, \delta_{\mathrm{ppm}}\right)$ : 3.97-4.13 (m, $\left.\mathrm{CH}_{2}\right)$; 4.19-4.34 (m, $\left.\mathrm{CH}_{2}\right)$; 7.20-7.27 (m, aromatic $\mathrm{H})$; 7.80-7.87 (m, aromatic $\mathrm{H})$; 7.93-7.96 (m, aromatic $\mathrm{H}) ; 8.77$ (s, iminic $\mathrm{H}$ ).

42BrFenReCl (C7). This complex was synthesized by a procedure similar to $\mathrm{C} 2$, but using ligand $\mathrm{L4}(0.55 \mathrm{mmol}, 0.24 \mathrm{~g})$ and $\mathrm{Re}(\mathrm{CO})_{5} \mathrm{Cl}$ (0.55 mmol, $\left.0.20 \mathrm{~g}\right)$. Calc: $\mathrm{C}, 31.02 ; \mathrm{H}, 1.64 ; \mathrm{N}$, 3.81. Found: $\mathrm{C}, 31.01 ; \mathrm{H}, 1.63 ; \mathrm{N}, 3.83$. FTIR $\left(\mathrm{KBr}, \mathrm{cm}^{-1}\right)$ : 2021, 1917 and $1886(\mathrm{CO}) ; 1635(\mathrm{C}=\mathrm{N}) .{ }^{1} \mathrm{H}-\mathrm{NMR}\left(\mathrm{CDCl}_{3}\right.$, $\left.\delta_{\text {ppm }}\right)$ : 4.10-4.25 (m, $\left.\mathrm{CH}_{2}\right) ; 4.25-4.40\left(\mathrm{~m}, \mathrm{CH}_{2}\right) ; 7.35-7.55(\mathrm{~m}$, aromatic $\mathrm{H}) ; 8.20-8.30$ (m, aromatic $\mathrm{H}) ; 8.90$ (s, iminic $\mathrm{H}$ ).

43ClFenReCl (C8). This complex was synthesized by a procedure similar to $\mathrm{C} 2$ but using ligand $\mathrm{L5}$ and $\mathrm{Re}(\mathrm{CO})_{5} \mathrm{Cl}(0.55$ mmol, 0.20 g). Calc: C, 35.28; H, 1.87; N, 4.33. Found: C, 35.28; $\mathrm{H}, 1.86 ; \mathrm{N}, 4.35$. FTIR (KBr, $\mathrm{cm}^{-1}$ ): 2021, 1917 and 1882 (CO); $1624(\mathrm{C}=\mathrm{N}) .{ }^{1} \mathrm{H}-\mathrm{NMR}\left(\mathrm{CDCl}_{3}, \delta_{\mathrm{ppm}}\right): 4.10-4.20\left(\mathrm{~m}, \mathrm{CH}_{2}\right) ; 4.30-$ $4.40\left(\mathrm{~m}, \mathrm{CH}_{2}\right) ; 7.50-7.80$ (m, aromatic $\left.\mathrm{H}\right) ; 8.85$ (s, iminic $\left.\mathrm{H}\right)$.

ClFenReBr (C9). This complex was synthesized by a procedure similar to $\mathrm{C} 2$, but using ligand $\mathrm{L6}$ (0.55 mmol, $0.24 \mathrm{~g}$ ) and $\operatorname{Re}(\mathrm{CO})_{5} \mathrm{Br}$ (0.55 mmol, $\left.0.22 \mathrm{~g}\right)$. Calc: $\mathrm{C}, 31.87 ; \mathrm{H}, 1.53 ; \mathrm{N}$, 3.54. Found: $\mathrm{C}, 31.86 ; \mathrm{H}, 1.53 ; \mathrm{N}, 3.56$. FTIR $\left(\mathrm{KBr}, \mathrm{cm}^{-1}\right)$ : 2025, 1913 and $1898(\mathrm{CO}) ; 1635(\mathrm{C}=\mathrm{N}) .{ }^{1} \mathrm{H}-\mathrm{NMR}\left(\mathrm{CDCl}_{3}\right.$, $\left.\delta_{\mathrm{ppm}}\right)$ : 4.10-4.20 (m, $\left.\mathrm{CH}_{2}\right) ; 4.55-4.60\left(\mathrm{~m}, \mathrm{CH}_{2}\right) ; 7.50-7.70(\mathrm{~m}$, aromatic $\mathrm{H}$ ); 8.25 (s, aromatic $\mathrm{H}) ; 8.85$ (s, iminic $\mathrm{H}$ ).

ClFenReBr' (C10). This complex was a new polymorph of C9. Calc: C, 31.87; H, 1.53; N, 3.54. Found: C, 31.86; H, 1.53; $\mathrm{N}$, 3.56. FTIR (KBr, $\mathrm{cm}^{-1}$ ): 2025, 1913 and 1898 (CO); 1635 $(\mathrm{C}=\mathrm{N})$.

\section{X-ray crystallography}

Single crystals of C2 to C10 suitable for X-ray diffraction analysis, were grown by slow vapor diffusion of $n$-hexane into dichloromethane solution of the complex. The ORTEP view of the complexes is shown in Fig. 1. Details of the crystal data col- lection and refinement parameters are summarized in Tables S1-S9. $\uparrow$ X-ray intensity data were collected using the full sphere routine by $\varphi$ and $\omega$ scans strategy on the Agilent SuperNova dual wavelength EoS S2 diffractometer with mirror monochromated Mo K $\alpha$ radiation $(\lambda=0.71073 \AA)$. For all data collections the crystals were cooled to $150(2) \mathrm{K}$ using an Oxford Diffraction Cryojet low-temperature attachment. The data reduction, including an empirical absorption correction using spherical harmonics, implemented in SCALE3 ABSPACK scaling algorithm, ${ }^{44}$ was performed using the CrysAlisPro software package. ${ }^{45,46}$ The crystal structures were solved by direct methods using the online version of AutoChem 2.0 in conjunction with $O L E X 2$ suite of programs implemented in the CrysAlis software, ${ }^{47}$ and then refined by full-matrix least-squares (SHELXL2014) on $F^{2} .^{48}$ The non-hydrogen atoms were refined anisotropically. All of the hydrogen atoms were positioned geometrically in idealized positions and refined with the riding model approximation, with $U_{\text {iso }}(\mathrm{H})=1.2 U_{\text {eq }}(\mathrm{C})$. For the molecular graphics the program SHELXTL was used. ${ }^{49}$ All geometric calculations were carried out using the PLATON software. ${ }^{50}$

In complex $\mathbf{C 7}$, the rhenium atom shows positional disorder over two sites with refined site occupancy 0.927(6)/ 0.073(6). In complex C10, there was a solvent accessible volume of $385 \AA$ is equal to almost 167 electrons which were not easy to model. The structure was squeezed and the contribution of these electrons in the unit cell was subtracted by back Fourier transform which was equal to almost two $n$-hexane molecules as solvent of recrystallization. CCDC 18714951871503 [C2 (1871495), C3 (1871497), C4 (1871498), C5 (1871496), C6 (1871497), C7 (18714501), C8 (18714500), C9 (18714502), C10 (18714503)] contain the supplementary crystallographic data for this paper.

\section{Computational chemistry}

All calculations were carried out using the Gaussian09 program $^{51}$ using the BP86-D3/def2-SV(P) level of theory. For the 

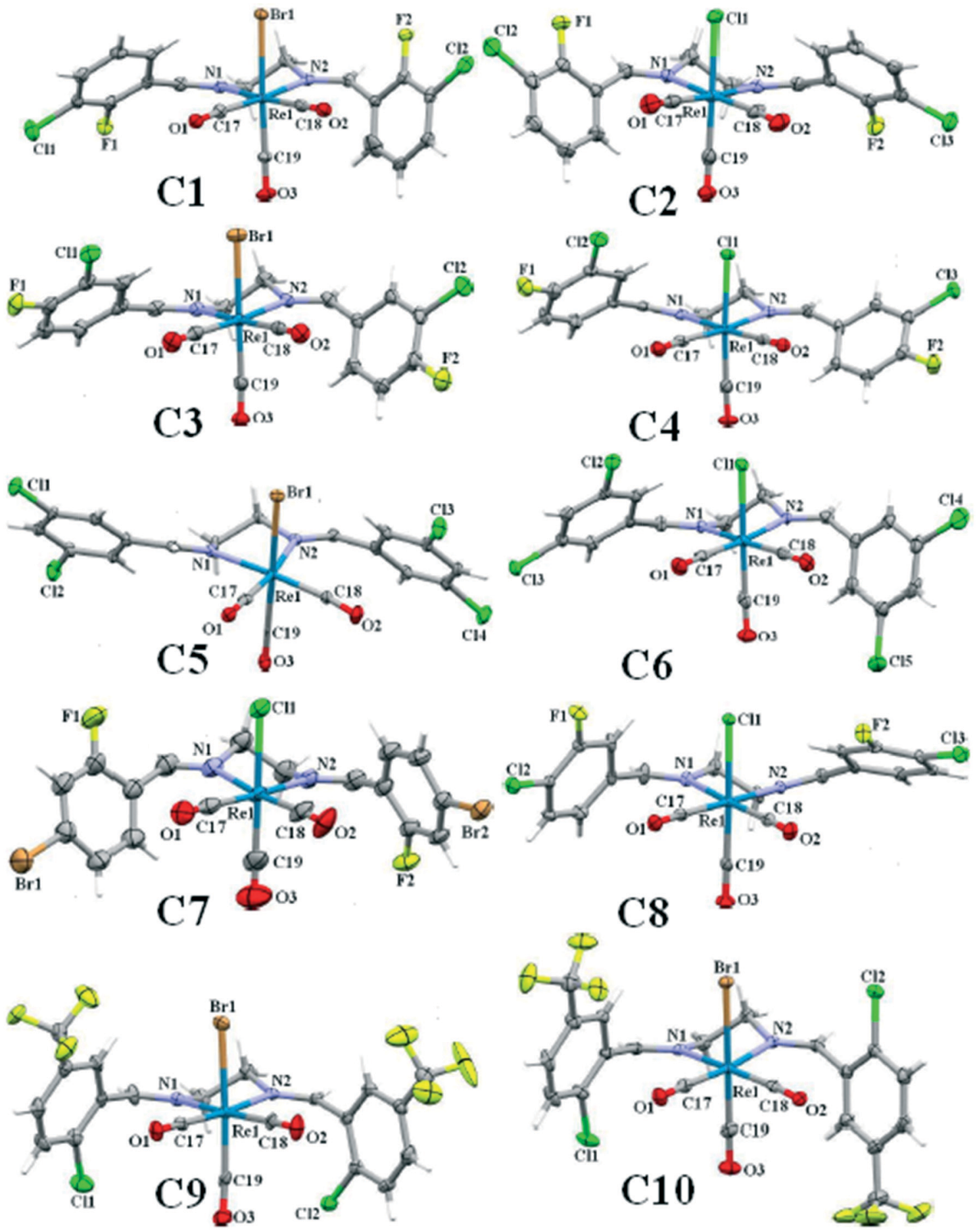

Fig. 1 The ORTEP view and selected atom numbering scheme of C1-C10 with 40\% ellipsoids probability.

calculations we have used the BP86 functional with the latest available Grimme correction functions for dispersion (D3). We have used the crystallographic coordinates as initial approximation for the theoretical analysis of the non-covalent interactions observed in the solid-state. This method has previously been successfully used to evaluate similar interactions. $^{52-55}$ The interaction energies were computed by calculating the difference between the energies of isolated monomers and their assembly. The interaction energies were corrected for the basis set superposition error (BSSE) using the counterpoise method. ${ }^{56}$ The molecular electrostatic potential (MEP) for each complex was also done by the Gaussian09 program with BP86-D3 function using def2-TZVP basis set (Fig. S17-S26 $\dagger$ ). ${ }^{57}$ The non-covalent interaction index $(\mathrm{NCI})^{58}$ of the intramolecular interactions was obtained by direct Gaussian cube file to NCI routine via total electron 
density function calculated with BP86-D3 level of theory using def2-TZVP basis set.

In order to better understand the nature of some of the intermolecular interactions such as hydrogen bonding based on the electron density and its Laplacian at bond critical points, the ground-state electronic wavefunctions obtained from Gaussian09 using BP86 level of theory and def2-SVP basis set for all atoms were used for calculations on the topology of the theoretical electron density based on quantum theory of atoms in molecules (QTAIM), including both local and integral properties, with the aid of the program AIM2000. ${ }^{59}$

\section{Hirshfeld surface analysis}

The quantitative analysis of the intermolecular interaction based on Hirshfeld surfaces calculations was studied. The Hirshfeld surfaces ${ }^{60}$ such as $d_{\text {norm }}$ and 2D fingerprint plots were generated using Crystal Explorer 3.1 and the crystallographically determined coordinates of the atoms in the structures. ${ }^{61}$ To keep internal consistency when comparing structures, the bond lengths of hydrogen atoms were normalized to standard neutron values $(\mathrm{C}-\mathrm{H}=1.083 \AA$, $\mathrm{O}-\mathrm{H}=0.983 \AA$, $\mathrm{N}-\mathrm{H}=1.009 \AA)$. The normalized contact distance $\left(d_{\text {norm }}\right)$ based on both $d_{\mathrm{e}}$ (the distance from a point on the surface to the nearest atom outside the surface) and $d_{\mathrm{i}}$ (the distance from a point on the surface to the nearest atom inside the surface) and van der Waals radii of the atom, given by eqn (1), enables the identification of the regions of particular importance to intermolecular interactions. The value of $d_{\text {norm }}$ is negative (red colour) or positive (blue colour) when intermolecular contacts are shorter or longer than the van der Waals separations of the designated atoms, respectively.

$$
d_{\text {norm }}=\frac{d_{\mathrm{i}}-r_{\mathrm{i}}^{\mathrm{vdW}}}{r_{\mathrm{i}}^{\mathrm{vdW}}}+\frac{d_{\mathrm{i}}-r_{\mathrm{i}}^{\mathrm{vdW}}}{r_{\mathrm{i}}^{\mathrm{vdW}}}
$$

A fingerprint plot is a $2 \mathrm{D}$ map that describes the nature and the type of intermolecular interactions quantitatively experienced by a molecule in the crystalline moiety in a convenient graphical format, which is unique for a given crystal structure. In addition, the similarities and dissimilarities between related crystal structures can be identified.

\section{Results}

\section{Crystal structure description}

General. The ORTEP view of the complexes is shown in Fig. 1. The crystal data and refinement parameters of C2-C10 were summarized in Table 1 . Selected bond lengths and angles are summarized in Table 2. The hydrogen bonding parameters of the complexes are summarized in Table 3. The crystal structure of all complexes comprises a molecule of rhenium complex in which a bidentate $\mathrm{N}, \mathrm{N}$-donor ligand, three carbonyl groups, in a facial arrangement, and an axial chloro or bromo group make up the coordination sphere of the Re center which exhibits a distorted octahedral geometry.
According to X-ray crystallographic data, compounds C2 and C3 are isomorphous (space group $P \overline{1}$ ), showing only slight changes of the unit cell dimensions (Tables S1 and S2 $\dagger$ ). Due to the importance of the intra- and intermolecular interactions in the crystal structure, the information of the crystal packing of each complex with all involved interactions and the packing index was discussed in detail. The packing index was calculated by PLATON. ${ }^{50}$ In each structure, the bite angle, the angle formed by the coordination of the bidentate $\mathrm{N}$, $\mathrm{N}$-donor ligand to metal centre (N1-Re1-N2), was reported.

32 ClFenReCl (C2). In the molecular structure of $\mathbf{C 2}$ the bite angle of the $\mathrm{N}, \mathrm{N}$-donor ligand is $77.77(17)^{\circ}$. One of the substituted arene rings (C11-C16), is significantly rotated comparing to the other arene ring due to the intramolecular C12-H12A $\cdots$ Cl1 hydrogen bonding, making a S(7) ring. The crystal packing shows intermolecular $\pi \cdots \pi$ interactions with centroid to centroid distances of 3.644(3) to 3.966(4) $\AA$. The crystal packing shows intermolecular $\mathrm{C} 7-\mathrm{H} 7 \mathrm{~A} \cdots \mathrm{O} 2$ and $\mathrm{C} 10-$ $\mathrm{H} 10 \mathrm{~A} \cdots \mathrm{Cl} 1$ hydrogen bonding in which the $\mathrm{Cl} 1$ atom is a bifurcated acceptor.

The intermolecular $\mathrm{C} 7-\mathrm{H} 7 \mathrm{~A} \cdots \mathrm{O} 2$ hydrogen bond connects the neighboring molecules into one-dimensional infinite chain along the $b$-axis. Alternatively, the chains are further consolidated by the intermolecular $\mathrm{C} 10-\mathrm{H} 10 \mathrm{~A} \cdots \mathrm{Cl} 1$ hydrogen bond, $\mathrm{Cl} 1 \cdots \mathrm{Cl} 3$ halogen bonding, $\mathrm{O} 2 \cdots \mathrm{Cl} 2$ and $\mathrm{Cl} 2 \cdots \mathrm{C} 7$ short contacts, forming a two-dimensional sheet running parallel to $a b$-plane (Fig. 2). The $\mathrm{Cl} 1 \cdots \mathrm{Cl} 3$ halogen bonding interaction is attractive. The packing index of $\mathrm{C} 2$ is $68.2 \%$.

34ClFReBr (C3). One of the substituted arene rings (C1C6) in C3, is significantly rotated comparing to the other due to the intramolecular $\mathrm{C} 2-\mathrm{H} 2 \cdots \mathrm{Br} 1$ hydrogen bonding, making a $\mathrm{S}(7)$ ring. The intermolecular $\mathrm{C} 7-\mathrm{H} 7 \cdots \mathrm{Br} 1$ and C15-H15 $\cdots$ O3 supported by antiparallel dipolar CO $\cdots \mathrm{CO}$ interactions linked molecules into a column parallel to $a c$-plane which are further connected by $\mathrm{C} 10-\mathrm{H} 10 \cdots \mathrm{O} 1$ interactions along the $b$-axis, forming a three-dimensional network (Fig. 3). The interesting feature of the crystal structure is the individual dimer formation by the intermolecular $\mathrm{Cl} 2 \cdots \mathrm{F} 2$ interactions which are more connected by the intermolecular Cl1 $\cdots \mathrm{C} 7$ and $\mathrm{C} 2 \cdots \mathrm{C} 2$ short contacts (Fig. S27†). The packing index of $\mathrm{C} 3$ is $67.9 \%$.

34ClFReCl (C4). The bite angle of the ligand is $78.4(2)^{\circ}$. One of the substituted arene rings (C11-C16), is significantly rotated comparing to the other arene ring due to the intramolecular $\mathrm{C} 2-\mathrm{H} 2 \mathrm{~A} \cdots \mathrm{Cl}$ 1 hydrogen bonding, making a $\mathrm{S}(7)$ ring. The intermolecular $\mathrm{C} 7-\mathrm{H} 7 \mathrm{~A} \cdots \mathrm{Cl} 1$ hydrogen bonding linked neighboring molecules into one-dimensional extended chain along the $b$-axis which was supported by the weak intermolecular $\mathrm{O} 2 \cdots \mathrm{C} 7$ short contacts (Fig. 4).

Pairs of weak intermolecular C15-H15A $\cdots$ O1 forming a head-to-tail individual dimers which are further connected to each other through the intermolecular C10-H10A $\cdots$ F1 interactions (Fig. S28†). The crystal packing also shows $\mathrm{Cl} 2 \cdots \mathrm{Cl} 2$ interactions which are shorter than the sum of the van der Waals radius of $\mathrm{Cl}[1.75 \AA]$ atoms. The packing index of $\mathrm{C4}$ is $69.9 \%$. 


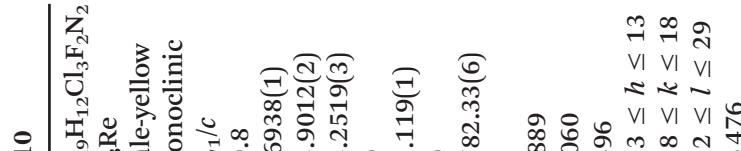

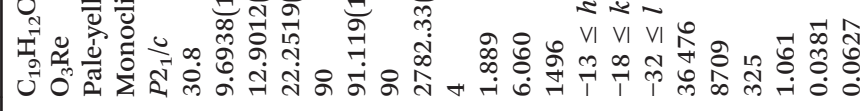

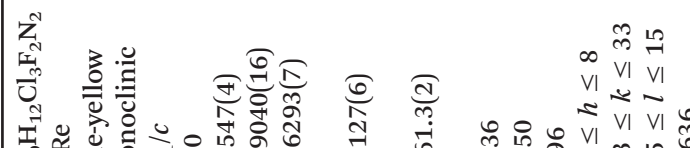

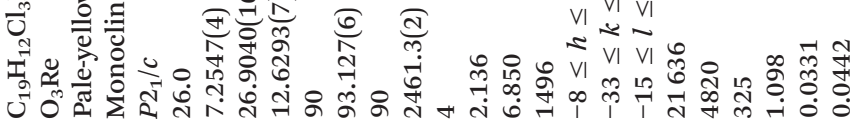

然

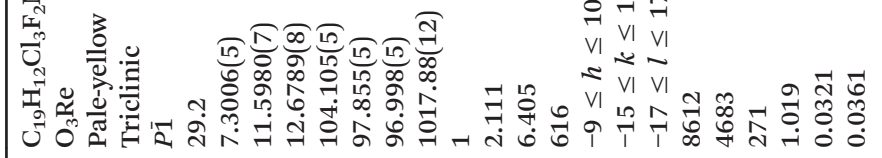

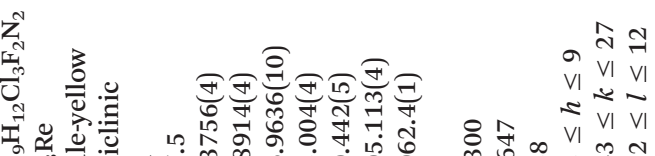

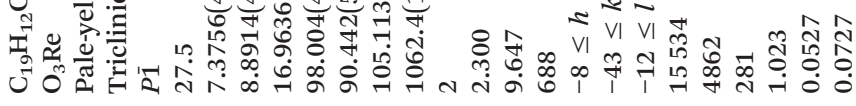

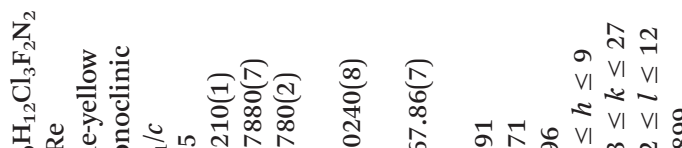

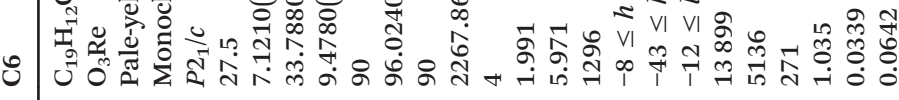

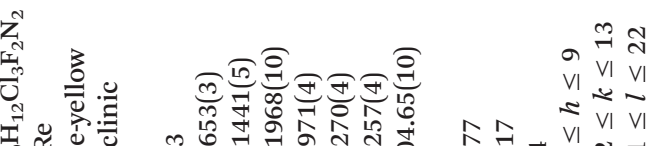

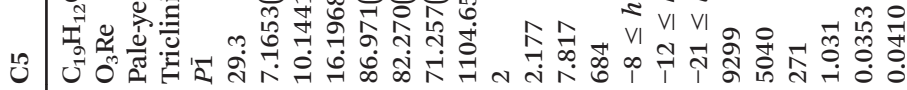

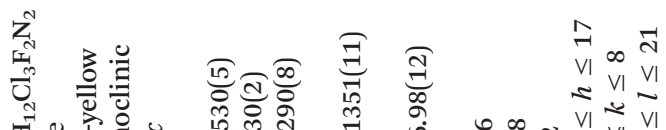

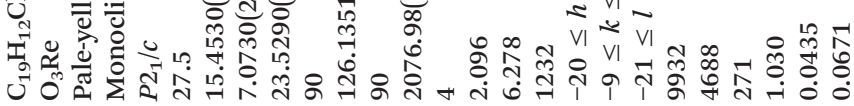

zat

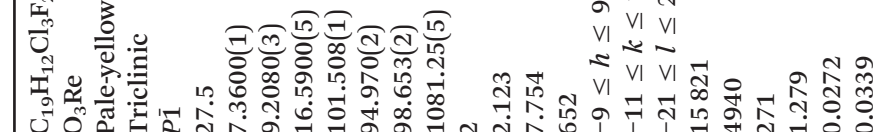

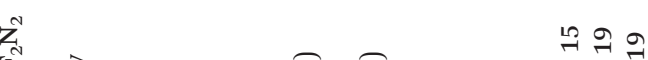

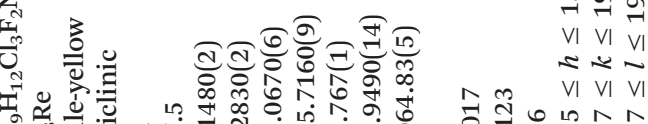

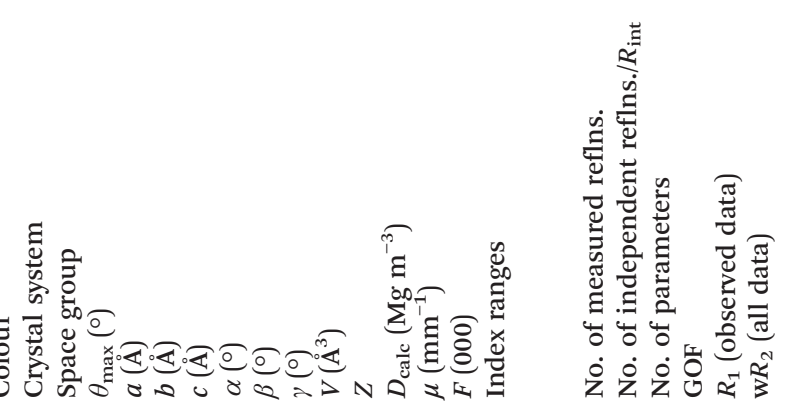


Table 2 Selected bond lengths and angles ( $\AA$, ०) of C2-C10

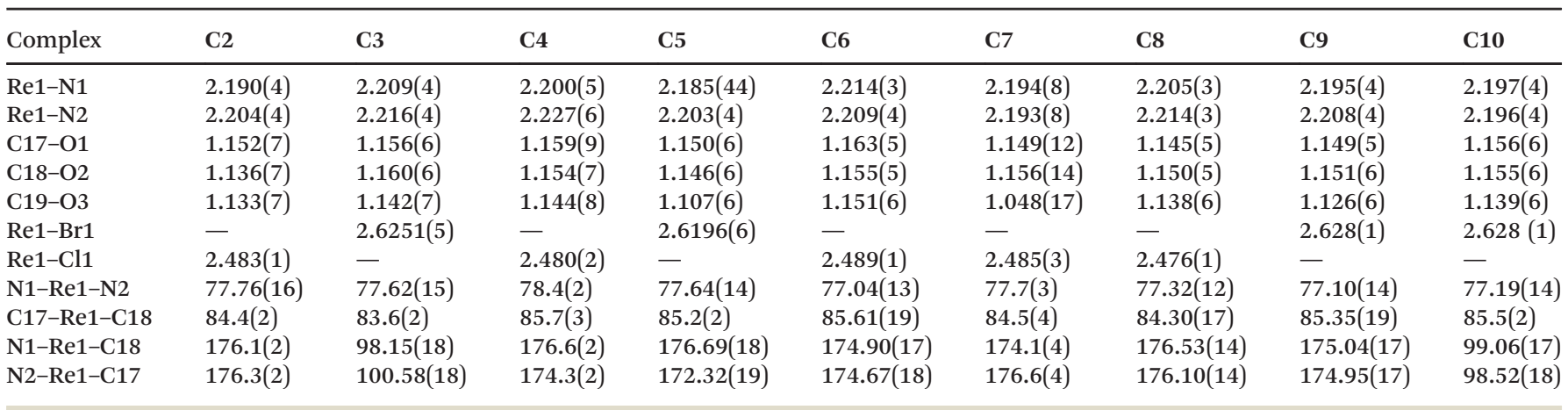

$35 \mathrm{ClenReBr}(\mathrm{C5})$. The bite angle of the ligand is $77.63(16)^{\circ}$. The orientation of the halogen-substituted arene ring is different to that in the other complexes with a torsion angle of almost $10^{\circ}$. The intermolecular $\mathrm{C} 4-\mathrm{H} 4 \cdots \mathrm{Cl} 3$ and $\mathrm{C} 14-$ $\mathrm{H} 14 \cdots \mathrm{Cl} 2$ interactions link neighboring head-to-tail arranged molecules into a one-dimensional extended chain along the

Table 3 Hydrogen bonding interactions parameters in complexes C1C10

\begin{tabular}{|c|c|c|c|c|}
\hline Complex & $\mathrm{D}-\mathrm{H} \cdots \mathrm{A}$ & $\mathrm{H} \cdots \mathrm{A}(\AA)$ & $\mathrm{D} \cdots \mathrm{A}(\AA)$ & $\mathrm{D}-\mathrm{H} \cdots \mathrm{A}\left({ }^{\circ}\right)$ \\
\hline \multirow[t]{3}{*}{ C1 } & $\mathrm{C} 2-\mathrm{H} 2 \cdots \mathrm{Br} 1$ & 2.78 & $3.691(7)$ & 161 \\
\hline & $\mathrm{C} 7-\mathrm{H} 7 \cdots \mathrm{Br}^{\mathrm{i}}$ & 2.91 & $3.846(7)$ & 170 \\
\hline & $\mathrm{C} 8-\mathrm{H} 8 \mathrm{~B} \cdots \mathrm{O} 2^{\mathrm{i}}$ & 2.47 & $3.263(10)$ & 137 \\
\hline \multirow[t]{3}{*}{$\mathrm{C} 2$} & $\mathrm{C} 12-\mathrm{H} 12 \mathrm{~A} \cdots \mathrm{Cl} 1$ & 2.62 & $3.520(6)$ & 163 \\
\hline & $\mathrm{C} 10-\mathrm{H} 10 \mathrm{~A} \cdots \mathrm{Cl}^{\mathrm{i}}$ & 2.71 & $3.627(6)$ & 169 \\
\hline & $\mathrm{C} 7-\mathrm{H} 7 \mathrm{~A} \cdots \mathrm{O} 2^{\mathrm{ii}}$ & 2.33 & $3.245(7)$ & 168 \\
\hline \multirow[t]{4}{*}{ C3 } & $\mathrm{C} 2-\mathrm{H} 2 \cdots \mathrm{Br} 1$ & 2.86 & $3.764(5)$ & 164 \\
\hline & $\mathrm{C} 7-\mathrm{H} 7 \cdots \mathrm{Br}^{\mathrm{i}}$ & 2.82 & $3.748(5)$ & 177 \\
\hline & $\mathrm{C} 10-\mathrm{H} 10 \cdots \mathrm{O} 1^{\mathrm{ii}}$ & 2.34 & $3.269(7)$ & 173 \\
\hline & $\mathrm{C} 15-\mathrm{H} 15 \cdots \mathrm{O} 3^{\mathrm{iii}}$ & 2.56 & $3.192(8)$ & 125 \\
\hline \multirow[t]{2}{*}{$\mathrm{C} 4$} & $\mathrm{C} 2-\mathrm{H} 2 \mathrm{~A} \cdots \mathrm{Cl} 1$ & 2.62 & $3.491(9)$ & 156 \\
\hline & $\mathrm{C} 7-\mathrm{H} 7 \mathrm{~A} \cdots \mathrm{Cl}^{\mathrm{ii}}$ & 2.61 & $3.519(7)$ & 165 \\
\hline \multirow[t]{5}{*}{ C5 } & $\mathrm{C} 6-\mathrm{H} 6 \cdots \mathrm{O} 3^{\mathrm{iii}}$ & 2.50 & $3.353(6)$ & 152 \\
\hline & $\mathrm{C} 7-\mathrm{H} 7 \cdots \mathrm{O} 3^{\text {iv }}$ & 2.60 & $3.240(6)$ & 127 \\
\hline & $\mathrm{C} 8-\mathrm{H} 8 \mathrm{~A} \cdots \mathrm{Br} 1^{\mathrm{v}}$ & 2.93 & $3.780(5)$ & 147 \\
\hline & $\mathrm{C} 8-\mathrm{H} 8 \mathrm{~A} \cdots \mathrm{O} 1^{\mathrm{vi}}$ & 2.53 & $3.318(6)$ & 138 \\
\hline & $\mathrm{C} 14-\mathrm{H} 14 \cdots \mathrm{Cl} 2$ & 2.83 & $3.744(5)$ & 169 \\
\hline \multirow[t]{5}{*}{ C6 } & $\mathrm{C} 2-\mathrm{H} 2 \mathrm{~A} \cdots \mathrm{Cl} 1$ & 2.64 & $3.531(5)$ & 161 \\
\hline & $\mathrm{C} 7-\mathrm{H} 7 \mathrm{~A} \cdots \mathrm{Cl}^{\mathrm{vi}}$ & 2.71 & $3.639(4)$ & 175 \\
\hline & $\mathrm{C} 8-\mathrm{H} 8 \mathrm{~B} \cdots \mathrm{O} 2^{\mathrm{vi}}$ & 2.52 & $3.369(6)$ & 168 \\
\hline & C10-H10A $\cdots$ O1 ${ }^{\text {vii }}$ & 2.45 & $3.369(6)$ & 168 \\
\hline & C14-H14A $\cdots 3^{\text {viii }}$ & 2.42 & $3.259(7)$ & 150 \\
\hline \multirow[t]{3}{*}{ C7 } & $\mathrm{C} 5-\mathrm{H} 5 \cdots \mathrm{O}^{\text {iv }}{ }^{.}$ & 2.55 & $3.255(16)$ & 132 \\
\hline & $\mathrm{C} 8-\mathrm{H} 8 \mathrm{~B} \cdots \mathrm{O} 2^{\mathrm{ii}}$ & 2.41 & $3.122(12)$ & 130 \\
\hline & C9-H9A $\cdots{ }^{1} 1^{\mathrm{i}}$ & 2.54 & $3.222(12)$ & 128 \\
\hline \multirow[t]{6}{*}{ C8 } & $\mathrm{C} 12-\mathrm{H} 12 \cdots \mathrm{Cl} 1$ & 2.57 & $3.461(5)$ & 159 \\
\hline & $\mathrm{C} 5-\mathrm{H} 5 \cdots \mathrm{O} 2^{\mathrm{ix}}$ & 2.57 & $3.290(6)$ & 135 \\
\hline & $\mathrm{C} 6-\mathrm{H} 6 \cdots \mathrm{O} 3^{\mathrm{x}}$ & 2.60 & $3.376(6)$ & 142 \\
\hline & $\mathrm{C} 7-\mathrm{H} 7 \cdots \mathrm{F} 1^{\mathrm{i}}$ & 2.37 & $3.291(5)$ & 173 \\
\hline & $\mathrm{C} 10-\mathrm{H} 10 \cdots \mathrm{F} 2^{\mathrm{i}}$ & 2.54 & $3.402(5)$ & 154 \\
\hline & $\mathrm{C} 16-\mathrm{H} 16 \cdots \mathrm{F} 2^{\mathrm{i}}$ & 2.55 & $3.384(5)$ & 149 \\
\hline \multirow[t]{3}{*}{ C9 } & $\mathrm{C} 7-\mathrm{H} 7 \cdots \mathrm{F} 1^{\mathrm{vi}}$ & 2.46 & $3.171(6)$ & 134 \\
\hline & C9-H9B $\cdots F 2^{x i}$ & 2.42 & $3.195(6)$ & 136 \\
\hline & $\mathrm{C} 15-\mathrm{H} 15 \cdots \mathrm{Br}^{\mathrm{xii}}$ & 2.88 & $3.696(5)$ & 148 \\
\hline C10 & $\mathrm{C} 4-\mathrm{H} 4 \cdots \mathrm{O} 3^{\mathrm{xiii}}$ & 2.54 & $3.224(10)$ & 129 \\
\hline
\end{tabular}

Symmetry codes: (i) $-1+x, y, z$ (ii) $x, 1+y, z$ (iii) $1-x, 1-y, 1-z$ (iv) $-x, 1-y, 1-z$ (v) $1-x,-y, 1-z$ (vi) $1+x, y, z$ (vii) $x, y,-1+z$ (viii) $-1+x, 1 / 2-y,-1 / 2+z$ (ix) $1-x, 1-y, 2-z$ (x) $-x, 1-y, 2-z$ (xi) $2-x, 1-y,-z$ (xii) $x, 3 / 2-y, 1 / 2+z$ (xiii) $-x, 1 / 2+y, 1 / 2-z$. $c$-axis which are interconnected further by the weak intermolecular $\mathrm{Cl} 1 \cdots \mathrm{Cl} 3$ halogen bond and $\mathrm{C} 2-\mathrm{H} 2 \cdots \mathrm{Br} 1$ to form a sheet (Fig. 5). Pair of intermolecular $\mathrm{C} 7-\mathrm{H} 7 \cdots \mathrm{O} 3$ and $\mathrm{C} 6-$ H6 $\cdots$ O1 hydrogen bonds form a centrosymmetric dimer, linking molecules into an infinite chain along the $a$-axis (Fig. S29†). The packing index of $\mathbf{C 5}$ is $69.9 \%$.

35ClenReCl (C6). The bite angle of the ligand is 77.04(13) ${ }^{\circ}$. The intramolecular $\mathrm{C} 2-\mathrm{H} 2 \mathrm{~A} \cdots \mathrm{Cl} 1$ interaction makes a $\mathrm{S}(7)$ ring. The intermolecular $\mathrm{C} 7-\mathrm{H} 7 \mathrm{~A} \cdots \mathrm{Cl} 1$ and $\mathrm{C} 8-\mathrm{H} 8 \mathrm{~B} \cdots \mathrm{O} 2$ interactions link neighboring molecules into onedimensional extended chains along the $a$-axis. The chains are further connected by the intermolecular $\mathrm{C} 14-\mathrm{H} 14 \mathrm{~A} \cdots \mathrm{O} 3$ and C10-H10A $\cdots \mathrm{O} 1$ interactions along $b$ and $c$-axis, respectively, forming a three-dimensional network. The interesting feature of the crystal packing is the intermolecular $\mathrm{Cl} 1 \cdots \mathrm{Cl} 3$ [3.425(2) $\AA]$ halogen bonding supported by the intermolecular $\mathrm{Cl} 2 \cdots \mathrm{C} 7$ interactions (Fig. 6). The packing index of $\mathrm{C6}$ is $67.3 \%$.

$42 \mathrm{BrFReCl}(\mathrm{C} 7)$. The bite angle of the ligand is $77.7(3)^{\circ}$. Pair of intermolecular $\mathrm{C} 5-\mathrm{H} 5 \cdots \mathrm{O} 3$ interactions makes a head-to-tail centrosymmetric dimer. The intermolecular C8$\mathrm{H} 8 \mathrm{~B} \cdots \mathrm{O} 2$ and $\mathrm{C} 9-\mathrm{H} 9 \mathrm{~A} \cdots \mathrm{O} 1$ connect the neighboring molecules into one-dimensional extended chains along the $b$-and $a$-axis, respectively, which are supported further by the intermolecular $\mathrm{CO}(\pi) \cdots \mathrm{Br}$ and $\mathrm{C} \cdots \mathrm{Br}$ interactions. The interesting feature of the crystal packing is the weak intermolecular $\mathrm{C} 15-\mathrm{H} 15 \cdots \mathrm{Cl} 1$ interaction and $\mathrm{F} 1 \cdots \mathrm{F} 2$ halogen bonding which link neighboring molecules into an extended chain in the [110] direction, furthermore the chains are interconnected head-to-tail through the intermolecular centrosymmetric $\mathrm{Cl} 1 \cdots \mathrm{Br} 2$ halogen bonding (Fig. 7). The packing index of $\mathrm{C} 7$ is $66.5 \%$.

$43 \mathrm{ClFReCl}(\mathrm{Cr})$. The bite angle of the ligand is $77.32(13)^{\circ}$. The intramolecular $\mathrm{C} 12-\mathrm{H} 2 \cdots \mathrm{Cl} 1$ interaction makes a $\mathrm{S}(7)$ ring. The intermolecular $\mathrm{C} 7-\mathrm{H} 7 \cdots \mathrm{F} 1$ and $\mathrm{C} 16-\mathrm{H} 16 \cdots \mathrm{F} 1$ interactions, link neighboring molecules into a onedimensional extended chain along the $a$-axis. The running head-to-tail chains are further interconnected through the intermolecular centrosymmetric $\mathrm{C} 5-\mathrm{H} 5 \cdots \mathrm{O} 2$ and $\mathrm{C} 6-\mathrm{H} 6 \cdots \mathrm{O} 3$ hydrogen bonds further supported by the intermolecular $\mathrm{Cl} 2 \cdots \mathrm{O} 2$ and $\mathrm{Cl} 3 \cdots \mathrm{C} 10$ short contacts, forming a threedimensional network (Fig. S30†). The interesting feature of the structure is the intramolecular Re-CO $\cdots \pi($ arene) interactions which has been explained in the theoretical section 


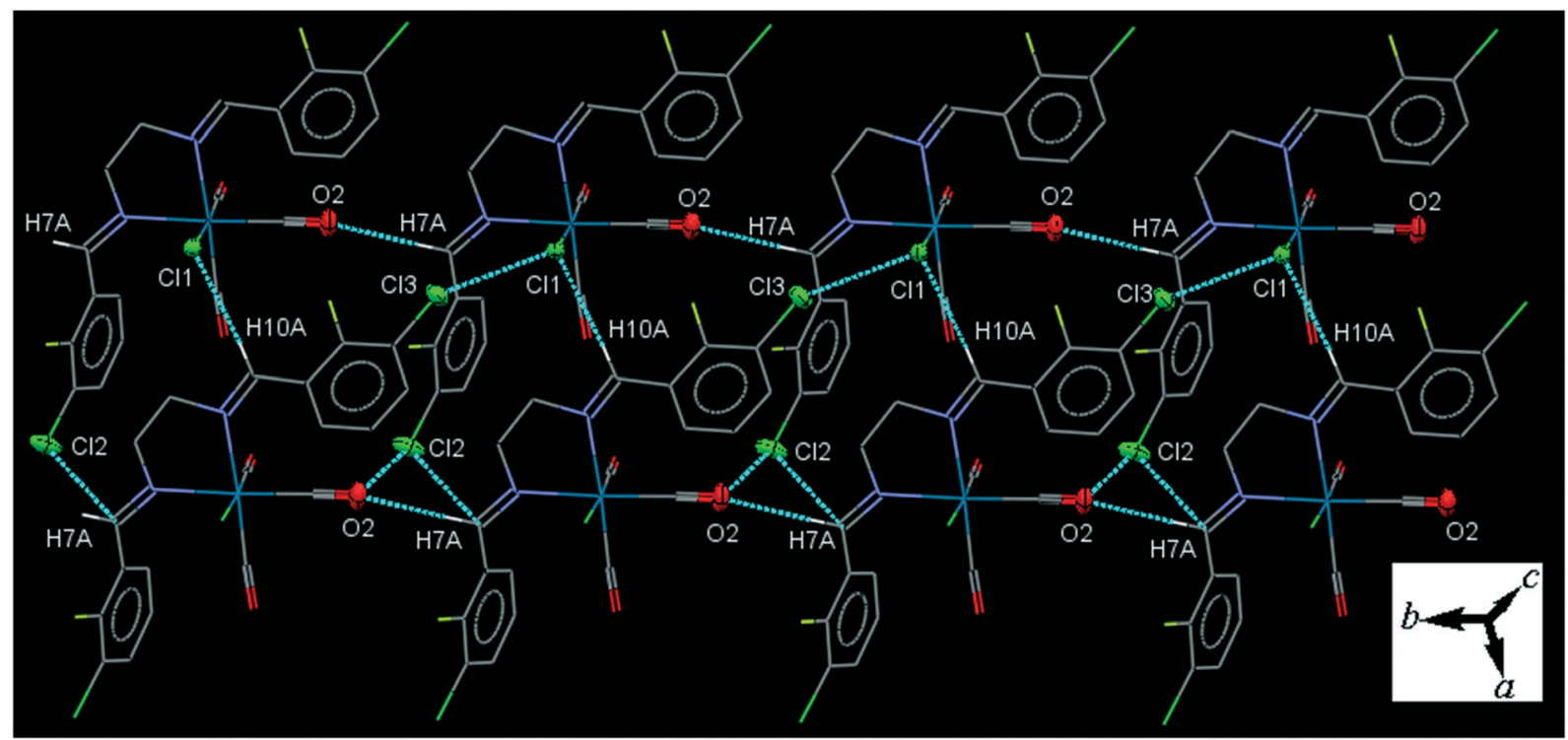

Fig. 2 The crystal packing of C2 viewed almost down the $c$-axis showing one-dimensional chains of molecules running along the $b$-axis and further consolidated by the intermolecular interactions into a sheet parallel to ab-plane. The $\mathrm{H}$-atoms not involved in the interactions omitted for clarity.

based on the molecular orbital calculations. Another interesting feature of the crystal structure is the intermolecular $\mathrm{Cl} 3 \cdots \mathrm{O} 2$ contact and $\mathrm{Cl} 2 \cdots \mathrm{Cl} 2$ halogen bond which connects neighboring molecule into a one-dimensional herringbone pattern (Fig. 8). The packing index of $\mathbf{C 8}$ is $71.2 \%$.

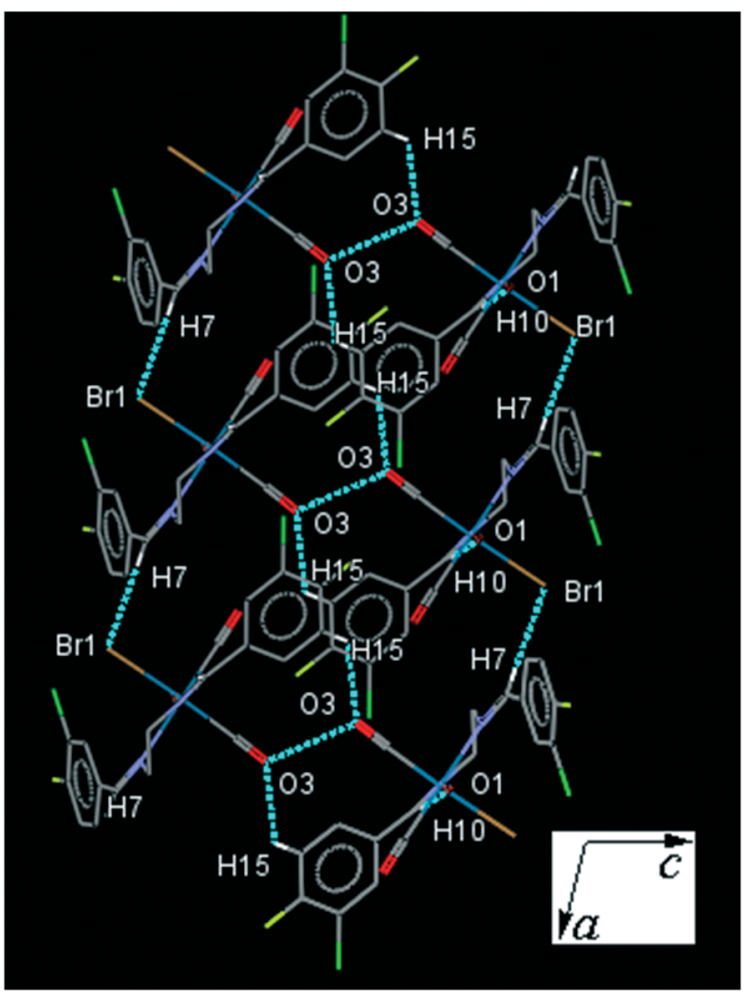

Fig. 3 Part of the crystal packing of $\mathrm{C} 3$ viewed down the $b$-axis, showing the connection of neighboring molecules through $\mathrm{C}-\mathrm{H} \cdots \mathrm{O}$, $\mathrm{C}-\mathrm{H} \cdots \mathrm{Cl}$ and antiparallel $\mathrm{CO} \cdots \mathrm{CO}$ interactions.
ClFReBr (C9). The bite angle of the ligand is $77.09(14)^{\circ}$. The intermolecular $\mathrm{C} 15-\mathrm{H} 15 \cdots \mathrm{Br} 1$ interaction connects neighboring molecules into a one-dimensional head-to-tail zig-zag extended chain along the $c$-axis (Fig. 9). The intermolecular $\mathrm{C} 7-\mathrm{H} 7 \cdots \mathrm{F} 1$ interaction link neighboring molecules into a one-dimensional extended chain along the $a$-axis and further the parallel chains are connected together through the intermolecular $\mathrm{C} 9-\mathrm{H} 9 \mathrm{~B} \cdots \mathrm{F} 2$ interaction (Fig. S31 $\dagger$ ).

The intermolecular $\mathrm{C} 4-\mathrm{H} 4 \cdots \mathrm{F} 6$ contact, links neighboring molecule into a one-dimensional herringbone-type extended chain along the $b$-axis (Fig. 10). The interesting feature of the crystal packing is the intermolecular $\mathrm{Cl} \cdots \mathrm{Cl}$ interaction which is significantly shorter, [3.196(2) $\AA$ ], than the sum of the van der Waals radius of $\mathrm{Cl}$ atoms [3.50 $⿱$ ] $]$. The packing index of C9 is $68.0 \%$.

ClFReBr' (C10). The bite angle of the ligand is 77.1(2) ${ }^{\circ}$. The intermolecular $\mathrm{C} 4-\mathrm{H} 4 \cdots \mathrm{O} 3$ interaction connects neighboring molecules into a one-dimensional head-to-tail extended chain along the $b$-axis which is supported by the very short $\mathrm{Cl} 1 \cdots \mathrm{O} 2$ contact (Fig. 11). An interesting feature of the crystal packing is the intermolecular $\mathrm{C}-\mathrm{F} \cdots \pi$ interaction which was further supported by the weak intermolecular $\mathrm{C} \cdots \mathrm{H}$ and $\mathrm{O} \cdots \mathrm{H}$ contacts (Fig. S32 $\dagger$ ). Additionally, the structure is uniquely supported by the intramolecular Re$\mathrm{CO} \cdots \pi$ (arene) interactions which are discussed in the theoretical section based on the molecular orbital calculations. The packing index of $\mathrm{C} 10$ is $68.0 \%$.

\section{Complexation energy, AIM and NCIPLOT data}

To obtain a better understanding of the contribution of intermolecular interactions toward the crystal packing, it is 


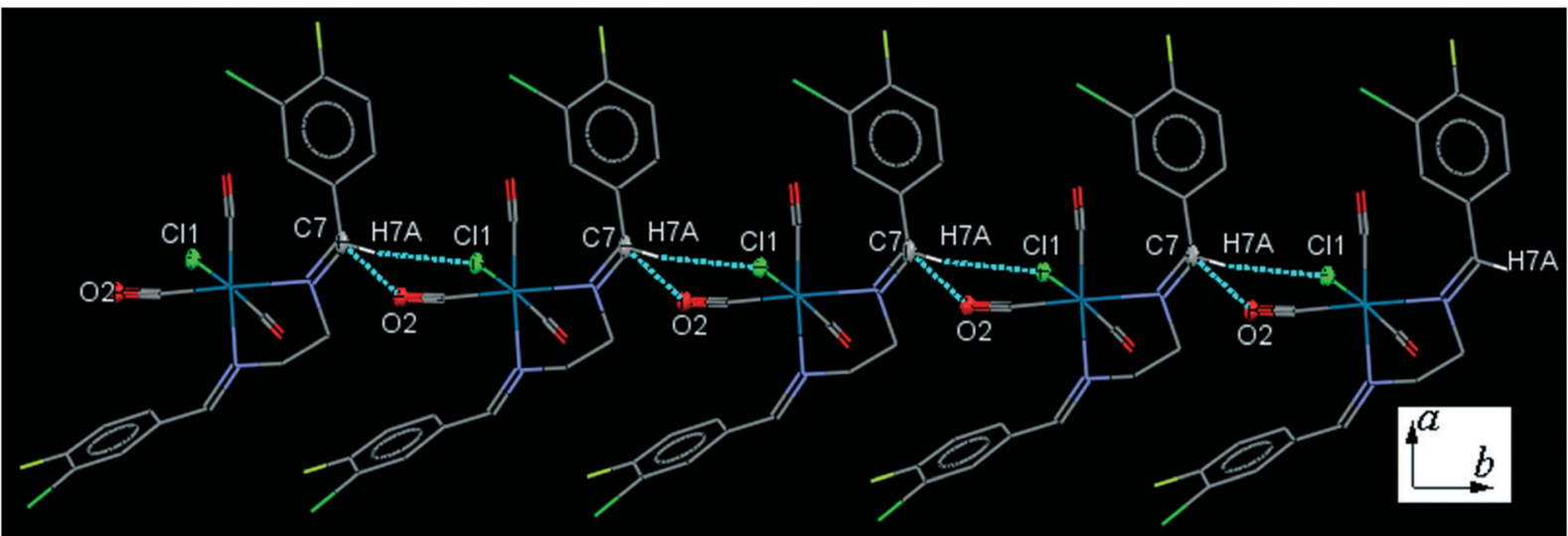

Fig. 4 Part of the crystal packing of $\mathrm{C} 4$ viewed down the $c$-axis, showing one-dimensional extended chain along the $b$-axis through intermolecular $\mathrm{C}-\mathrm{H} \cdots \mathrm{Cl}$ and $\mathrm{C} \cdots \mathrm{O}$ interactions.

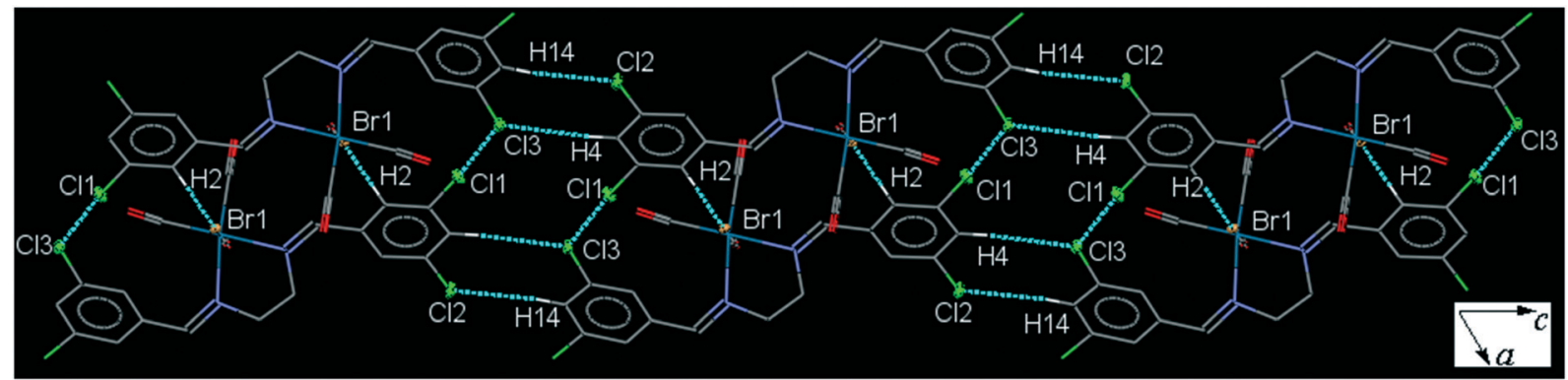

Fig. 5 Part of the crystal packing of $\mathrm{C} 5$, viewed down the $b$-axis, showing parallel chain formation through the intermolecular $\mathrm{C}-\mathrm{H} \cdots \mathrm{Cl}$ interactions which are by $\mathrm{Cl} \cdots \mathrm{Cl}$ short contacts.

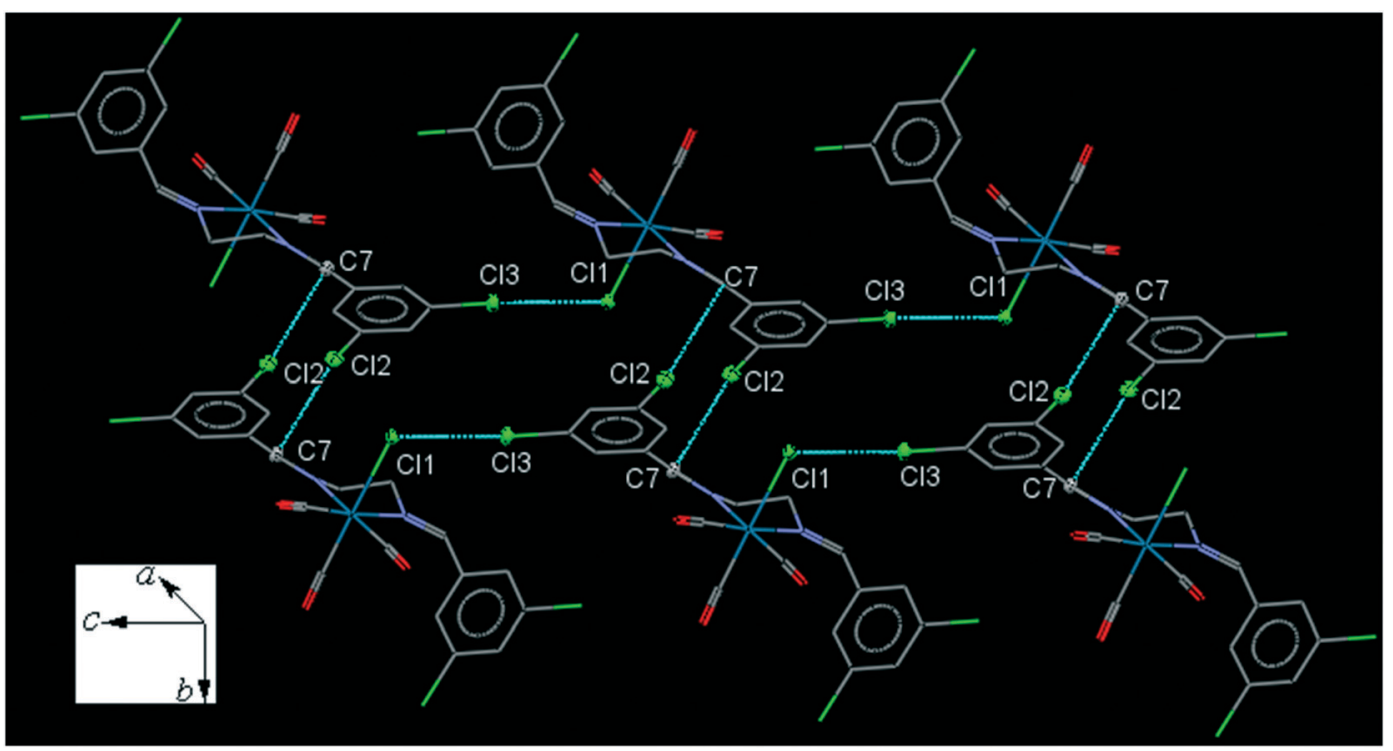

Fig. 6 Part of the crystal packing of $\mathrm{C}$, showing connection of molecules into a parallel chain through the intermolecular $\mathrm{C} \cdots \mathrm{Cl}$ and $\mathrm{Cl} \cdots \mathrm{Cl}$ interactions.

important to obtain quantitative insights into the nature and energy of these interactions. We have focused on the theoretical calculation of the interesting supramolecular assemblies observed in the solid-state of all the structures described above on the basis of the dimers formed by the desired intermolecular interactions. The complexation energies of the important crystallographic fragments based on their related intermolecular interactions are summarized in Table 4; as a 


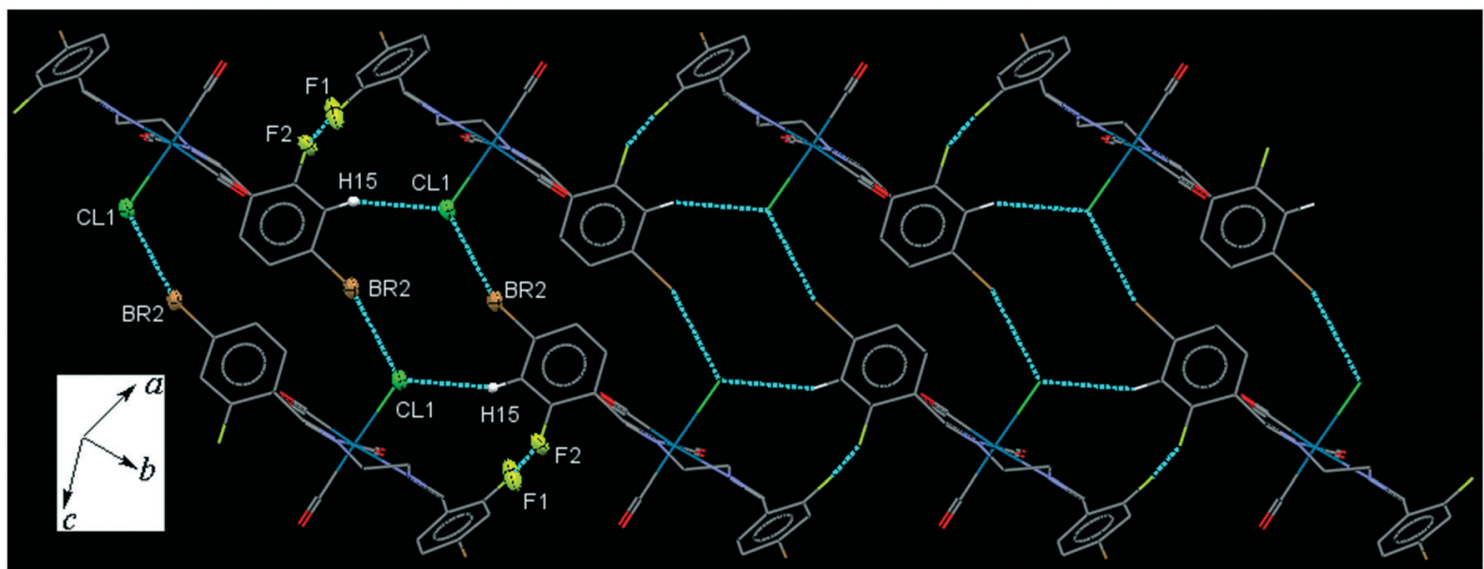

Fig. 7 Part of the crystal packing of $\mathrm{C}$, showing interconnected chains of neighboring molecules through the intermolecular $\mathrm{Cl} \cdots \mathrm{Br}$ halogen bond along [110] direction.

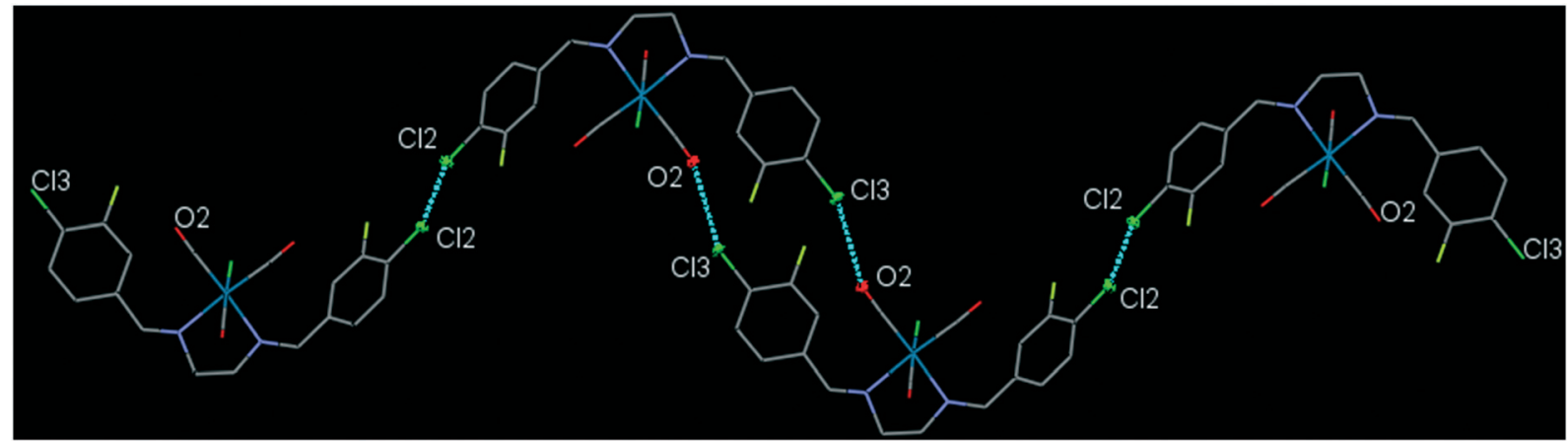

Fig. 8 Part of the crystal packing of $\mathrm{C} 8$, showing one-dimensional herringbone extended chain of molecules through the intermolecular $\mathrm{Cl} \cdots \mathrm{O}$ and $\mathrm{Cl} \cdots \mathrm{Cl}$ contacts.

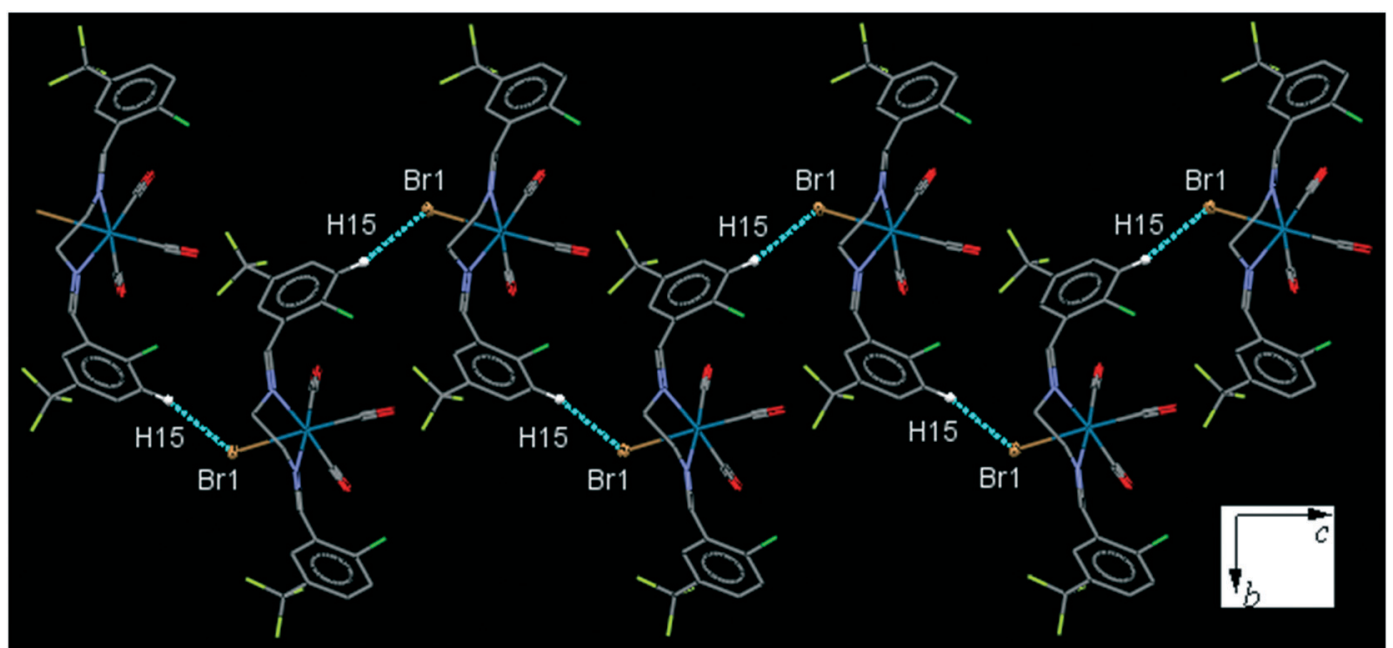

Fig. 9 Part of the packing of C9, showing zig-zag connection of molecules into one-dimensional extended chain along the c-axis through C$\mathrm{H} \cdots \mathrm{Br}$ interaction.

caveat, the energies quoted should not be treated as absolute but do put the interactions on a relative scale and provide "ball park" values for the energies. Some of the important crystallographic dimers formed by their related inter- molecular interactions are shown in Fig. 12. As it is clear from Table 4, the dimers formed by the cooperative interactions and metal-bound halogen (e.g. dimer1 in C1; dimer4 in C2; dimer4 in C3; dimer2 in C4; dimer6 in C5; dimer3 in C6; 


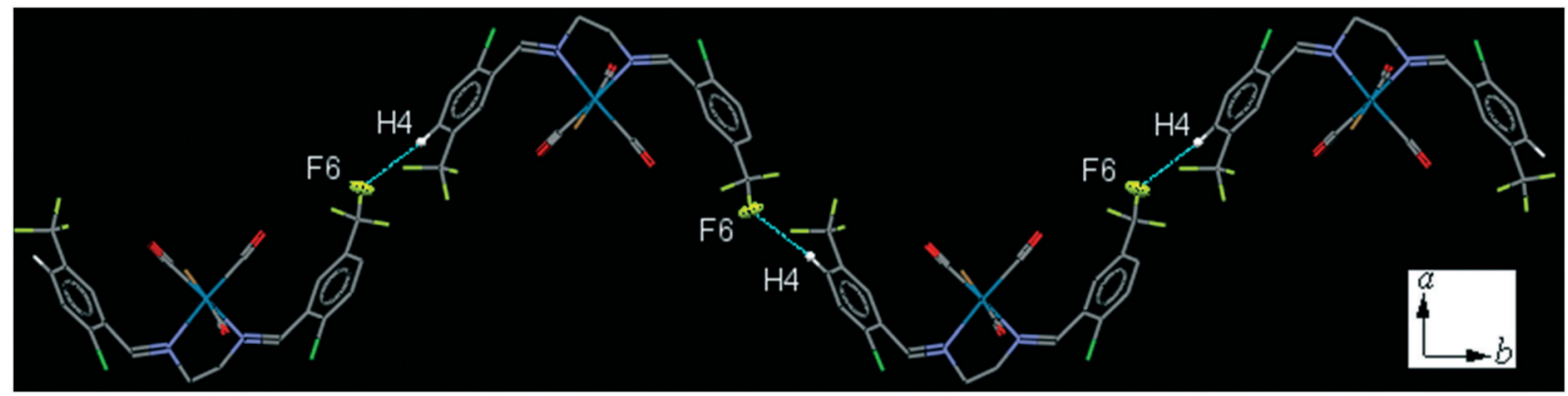

Fig. 10 Part of the crystal packing of C9, showing one-dimensional herringbone-type extended chain along the b-axis through the intermolecular

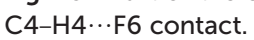

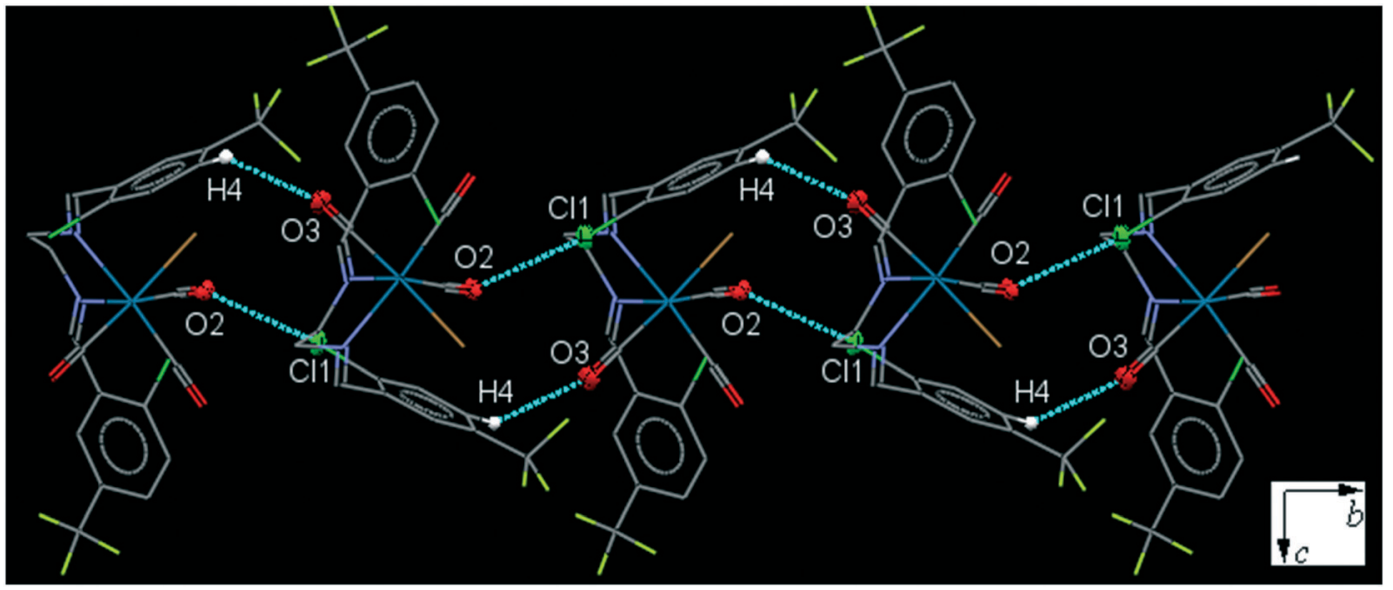

Fig. 11 One-dimensional extended chain of $\mathrm{C} 10$ along the $b$-axis through intermolecular $\mathrm{C}-\mathrm{H} \cdots \mathrm{O}$ and $\mathrm{Cl} \cdots \mathrm{O}$ interactions.

dimer4 in $\mathbf{C 8}$ and dimer3 in C10) the interaction energies are significant and negative, confirming their strong binding motifs in the solid-state structures. In case of $\mathbf{C 9}$ and C10, the contribution of the trifluoromethyl group involved in the $\mathrm{H} \cdots \mathrm{F}$ interactions is also significant.

In all halogen-halogen interactions with the more linear type I contacts (dimer1 in $\mathbf{C 2}$, dimer2 in $\mathbf{C 3}$, dimer1 in $\mathbf{C 4}$, dimer1 in C6, dimer6 in C7, dimer2 in C8 and dimer2 in C9), in which regions with a partial positive charge on both halogens are in close proximity, the complexation energy is negligible and the interaction is not electrostatically favored. In type II contacts involving an approach of the region with a partial negative charge on one halogen atom to the region of partial positive charge on another, the interaction energy are significant (Table 4). The theoretical models of the important binding motifs in each complex are shown in Fig. S33a-j. $\uparrow$ On the other hand, there are some non-classic hydrogen bonds in C2, C5 and C9 and also a halogen bonding in C8 which contribute significantly to the interaction energies. To pursue the nature of such interaction we used AIM calculations. The values of electron density, $\rho_{\mathrm{b}}$, Laplacian of electron density, $\nabla^{2} \rho_{\mathrm{b}}$, at the bond critical point (BCP) are the parameters that are usually used to characterize the nature of a chemical bond. These values for the BCP of the aforementioned hydrogen bonding and halogen bonding of the related dimers have been listed in Table 5 . We have also calculated these dimers using other level of theory such as B97D3/def2SVP and MP2/ def2-TZVP and the interaction energy is in the same range, giving reliability to the level of theory used. To better show the role of the metal-bound halogen in the intermolecular interactions in some of these complexes, the molecular electrostatic potential of C4, C6, C8 and C10 are shown in Fig. 13. It is clear that there is significant negative electrostatic charge at metal-bound halogen position comparing to the carbonbound halogen with more electrophilic character.

Another interesting feature of the crystal structure of these complexes is the presence of the intramolecular Re-CO(lone pair) $\cdots \pi$ (arene) interactions. In spite of their inherent weak nature, it has been shown that $\mathrm{M}-\mathrm{CO}$ (lone pair) $\cdots \pi$ (arene) interactions are relevant in some transition metal carbonyl complexes which provide a measure of stability in their crystal structure. ${ }^{28-30}$ Besides the possibility of the different type of the intermolecular interactions in these complexes, we have tuned the electronic nature of the arene rings in the starting aldehydes by substituting different halogens at different positions. The shortest intramolecular Re-CO(lone pair) $\cdots \pi$ (arene) interactions were found in C8 and C10. In case of other complexes, the orientation of the substituted arene rings was affected by the other intermolecular interactions in the crystal packing so that there is not suitable short 
Table 4 The interaction energies of the selected dimers

\begin{tabular}{|c|c|c|}
\hline Complex & $\begin{array}{l}\text { Dimers } \\
\text { (intermolecular interactions) }\end{array}$ & $\begin{array}{l}\text { BP86-D3/def2-SV(P) } \\
\text { energy }\left(\mathrm{kcal} \mathrm{mol}^{-1}\right)\end{array}$ \\
\hline \multirow[t]{2}{*}{ C1 } & Dimer1: $\mathrm{H} 4 \cdots \mathrm{Br} 1, \mathrm{H} 6 \cdots \mathrm{O} 3, \mathrm{O} 2 \cdots \mathrm{F} 1$ & -14.66 \\
\hline & Dimer2: $\mathrm{C} 12 \cdots \mathrm{F} 2$ & -19.58 \\
\hline \multirow[t]{4}{*}{$\mathrm{C} 2$} & Dimer1: $\mathrm{Cl}^{1} \cdots \mathrm{Cl}^{3}, \mathrm{Cl}^{2} \cdots \mathrm{O} 2$ & -3.30 \\
\hline & Dimer2: CO $\cdots \mathrm{CO}$ & -5.03 \\
\hline & Dimer3: H7A $\cdots \mathrm{O} 2$ & -6.55 \\
\hline & Dimer4: $\mathrm{H} 10 \mathrm{~A} \cdots \mathrm{Cl}^{1}$ & -15.61 \\
\hline \multirow[t]{4}{*}{ C3 } & Dimer1: $\mathrm{H} 15 \cdots \mathrm{O} 3, \mathrm{H} 16 \cdots \mathrm{O} 3, \mathrm{CO} \cdots \mathrm{CO}$ & -6.17 \\
\hline & Dimer2: $\mathrm{F} 2 \cdots \mathrm{Cl} 2$ & 0.05 \\
\hline & Dimer3: $\mathrm{H} 10 \cdots \mathrm{O} 1$ & -7.28 \\
\hline & $\begin{array}{l}\text { Dimer4: } \mathrm{H} 7 \cdots \mathrm{Br} 1, \mathrm{H} 8 \mathrm{~B} \cdots \mathrm{O} 2 \\
\mathrm{C} 10 \cdots \mathrm{Cl} 2\end{array}$ & -16.53 \\
\hline \multirow[t]{4}{*}{$\mathrm{C} 4$} & Dimer1: $\mathrm{Cl}^{2} \cdots \mathrm{Cl}^{2}$ & -0.10 \\
\hline & Dimer2: $\mathrm{H}_{7 \mathrm{~A}} \cdots \mathrm{Cl}^{1}, \mathrm{O} 2 \cdots \mathrm{C} 7, \mathrm{H} 8 \mathrm{~B} \cdots \pi$ & -18.98 \\
\hline & Dimer3: F2 $\cdots \mathrm{Cg}$ & -2.66 \\
\hline & Dimer4: H15A $\cdots \mathrm{O} 1$ & -1.78 \\
\hline \multirow[t]{6}{*}{ C5 } & Dimer1: $\mathrm{Cl}^{1} \cdots \mathrm{Cl}^{3}$ & -8.27 \\
\hline & Dimer2: $\mathrm{H} 14 \cdots \mathrm{Cl}^{2}$ & -3.05 \\
\hline & Dimer3: $\mathrm{H} 7 \cdots \mathrm{O} 3$ & -20.78 \\
\hline & Dimer4: $\mathrm{H} 5 \cdots \mathrm{O} 3$ & -12.31 \\
\hline & Dimer5: H8B $\cdots \mathrm{O} 1$ & -13.91 \\
\hline & Dimer6: H8A $\cdots \mathrm{Br} 1$ & -29.66 \\
\hline \multirow[t]{4}{*}{ C6 } & Dimer1: $\mathrm{Cl}^{1} \cdots \mathrm{Cl}^{3}$ & -4.60 \\
\hline & Dimer2: $\mathrm{C} 7 \cdots \mathrm{Cl}^{2}$ & -16.61 \\
\hline & $\begin{array}{l}\text { Dimer3: } \mathrm{H}_{7} \mathrm{~A}^{\cdots} \mathrm{Cl}^{1}, \mathrm{H} 8 \mathrm{~B} \cdots \mathrm{O} 2 \\
\mathrm{C} 10 \cdots \mathrm{Cl} 4\end{array}$ & -16.45 \\
\hline & Dimer4: $\mathrm{H} 14 \cdots \mathrm{O} 3$ & -1.82 \\
\hline \multirow[t]{7}{*}{ C7 } & Dimer1: $\mathrm{Br} 1 \cdots \mathrm{O} 3$ & -7.21 \\
\hline & Dimer2: $\mathrm{H} 5 \cdots \mathrm{O} 3$ & -4.68 \\
\hline & Dimer3: $\mathrm{H} 8 \mathrm{~B} \cdots \mathrm{O} 2$ & -6.61 \\
\hline & Dimer4: H9A $\cdots \mathrm{O} 1$ & -13.77 \\
\hline & Dimer5: $\mathrm{Cl}^{1} \cdots \mathrm{Br} 2$ & -10.98 \\
\hline & Dimer6: $\mathrm{F} 1 \cdots \mathrm{F} 2$ & -4.61 \\
\hline & Dimer7: $\mathrm{Br} 2 \cdots \mathrm{Cg}$ & -10.24 \\
\hline \multirow[t]{8}{*}{ C8 } & Dimer1: $\mathrm{Cg} 2 \cdots \mathrm{Cl}^{2}$ & -9.82 \\
\hline & Dimer2: $\mathrm{Cl}^{2} \cdots \mathrm{Cl}^{2}$ & 0.05 \\
\hline & Dimer3: $\mathrm{Cl}^{2} \cdots \mathrm{O} 2$ & -1.47 \\
\hline & Dimer4: $\mathrm{Cl}^{1} \cdots \mathrm{C} 10$ & -26.11 \\
\hline & Dimer5: $\mathrm{H} 5 \cdots \mathrm{O} 2$ & -7.71 \\
\hline & Dimer6: $\mathrm{H} 6 \cdots \mathrm{O} 3$ & -8.00 \\
\hline & Dimer7: $\mathrm{H} 10 \cdots \mathrm{F} 2, \mathrm{H} 16 \cdots \mathrm{F} 2 \& \mathrm{H} 7 \cdots \mathrm{F} 1$ & -15.56 \\
\hline & Dimer8: $\mathrm{H} 15 \cdots \mathrm{O} 2$ & -16.32 \\
\hline \multirow[t]{5}{*}{ C9 } & Dimer1: $\mathrm{Cl}^{1} \cdots \mathrm{Cl}^{1}$ & -0.17 \\
\hline & Dimer2: $\mathrm{H} 4 \cdots \mathrm{F} 6$ & -2.86 \\
\hline & Dimer3: H7 $\cdots$ F1 & -15.35 \\
\hline & Dimer4: H9B $\cdots$ F2 & -13.15 \\
\hline & Dimer5: H15 $\cdots \mathrm{Br} 1$ & -9.72 \\
\hline \multirow[t]{4}{*}{ C10 } & Dimer1: $\mathrm{Cl}^{2} \cdots \mathrm{O} 2$ & -7.41 \\
\hline & Dimer2: F5 $\cdots \mathrm{C} 7$ & -4.28 \\
\hline & $\begin{array}{l}\text { Dimer3: H8A } \cdots \text { O1, H8B } \cdots \text { Br1, } \\
\text { F3 } \cdots \text { C11 \& C18 } \cdots \text { H9A }\end{array}$ & -18.13 \\
\hline & Dimer4: $\mathrm{Cl}^{1} \cdots \mathrm{O} 2$ \& $\mathrm{H} 4 \cdots \mathrm{O} 3$ & -3.10 \\
\hline
\end{tabular}

Re-CO $\cdots \pi$ contacts. In fact, the X-ray crystal structures of complexes C1-C10 show the Re-CO $\cdots \pi$ contacts from 3.059 to $3.586 \AA$. As in the previously studied systems, ${ }^{30}$ the shortest intramolecular Re-CO $\cdots \pi$ distance was found in C8 with fluoro and chloro substituents and in $\mathbf{C 1 0}$ with trifluoromethyl substituents which enhance the $\pi$-acidity of the aromatic rings. The crystallographic results were also rationalized by examining NCIPLOT graphical data and also from DFT calculations using molecular orbitals analyses (Fig. 14).
Fig. 14c and d show a detailed non-covalent interactions map using reduced density gradient iso-surface (NCI-RDG) with the color scale chosen to be, $-0.03<\rho \times \operatorname{sign}\left(\lambda_{2}\right)<0.03$ a.u., for the short intramolecular $\mathrm{CO} \cdots \pi$ interactions in $\mathbf{C 8}$ and C10. The iso-surface plot clearly shows the presence of the weak intramolecular interactions. In order to confirm this behavior we have carried out a theoretical calculation using Gaussian09 program with BP86-D3 function and def2-TZVP basis set. In particular, we have calculated all molecular orbitals of complexes C8 and C10 in order to clarify the differences based on the molecular orbital interactions to explain their short $\mathrm{CO} \cdots \pi$ interactions. Interestingly, in some of the calculated molecular orbitals of the substituted arene ring we have found small but noteworthy contributions from the atomic orbitals of the interacting CO. This confirms that the $\pi$-antibonding orbitals ( $\mathrm{H}-3$ in $\mathrm{C8}$ and $\mathrm{H}-4$ in C10) and $\pi$-bonding orbital ( $\mathrm{H}-3$ in $\mathrm{C10}$ ) have atomic contributions from the CO co-ligand (Fig. 14e-g). Therefore, it can be concluded that there are lone-pair $\cdots \pi$ interactions in complexes C8 and C10. We have also investigated these intramolecular interactions by AIM through bond path between the carbonyl groups of complexes $\mathbf{C 8}$ and $\mathbf{C 1 0}$ with the related arene rings. In both cases, there are bond paths with the related BCP between the carbon atom of the carbonyl groups and carbon atom of the arene rings with $\rho_{\mathrm{b}}=0.01$ a.u. and $\nabla^{2} \rho_{\mathrm{b}}=0.032$ a.u. in C8 and C10 (Fig. S34 $\dagger$ ), confirming the closed shell interactions but because of the long distance of the oxygen atom of the carbonyl group from the carbon atom of the arene ring, AIM does not show bond path between them although the presence of these weak interactions were confirmed by NCI index and molecular orbital calculations. In case of molecular orbital calculations we also found the contribution of the atomic orbitals of the fragments in these complexes by dividing each complex to six fragments, namely, the metal centre $(\mathrm{Re})$, the axial $\mathrm{X}$ group $(-\mathrm{Cl}$ in $\mathbf{C 8}$ and $-\mathrm{Br}$ in $\mathrm{C10}$ ), the axial $\mathrm{CO}$ group, the equatorial $\mathrm{CO}$ groups, and the diimine ligand (Table 6). In C8, it can be seen from Table 6 that the fragment orbital of $\mathrm{CO}_{\text {eq2 }}(\mathrm{p}$ orbital of oxygen) and the ligand ( $\pi^{*}$ orbital) have 1.3 and 94.2 percentage in $\mathrm{H}-3$ and they can interact to each other (Fig. 14e). In C10, the fragment orbital of $\mathrm{CO}_{\mathrm{eq} 1}$ (p orbital of oxygen) contributed $2.9 \%$ in $\mathrm{H}-3$ and interact with the right hand side arene ring. Of the $40.3 \%$ of the ligand in $\mathrm{H}-3$, only $26 \%$ is located on right hand side arene ring, $7 \%$ on the left one and the rest on ethylenediimine segment. On the other hand, in $\mathrm{H}-4$, the fragment orbital of $\mathrm{CO}_{\text {eq2 }}(\mathrm{p}$ orbital of oxygen) contributed $0.7 \%$ to the interaction with left hand side arene ring (Fig. 14g) with $88.4 \%$ contribution of the diimine ligand of which almost $86 \%$ is donated by the arene ring and the rest is only located on the ethylenediamine segment.

Furthermore, we also studied the nature and relative strength of the halogen-bonding interactions in all complexes using a reduced density gradient iso-surface (NCI-RDG) with respect to $\rho \times \operatorname{sign}\left(\lambda_{2}\right)$ by color scale. The intermolecular interaction iso-surfaces generated by NCIPLOT for $s=0.3$ and 


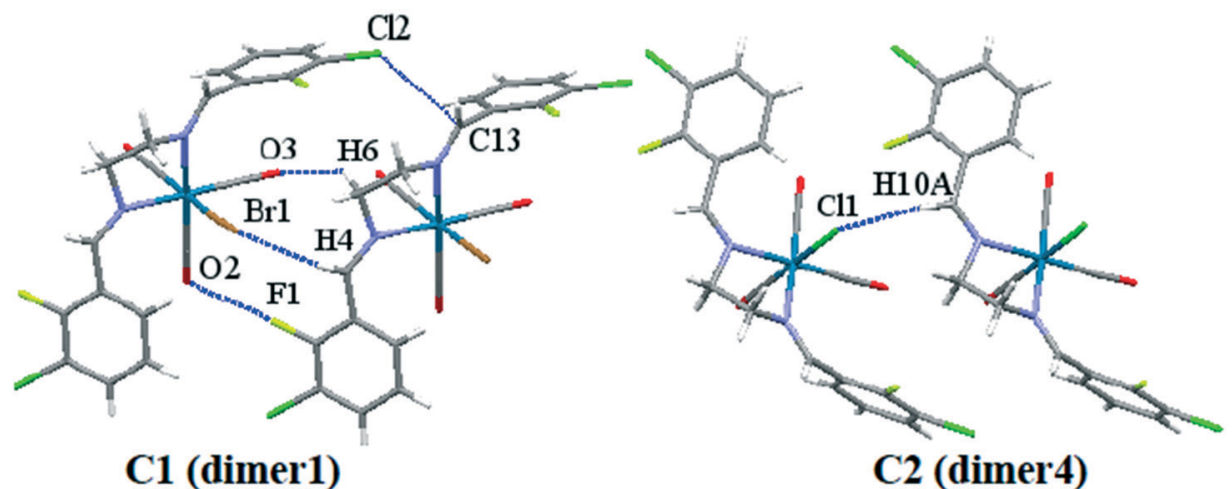

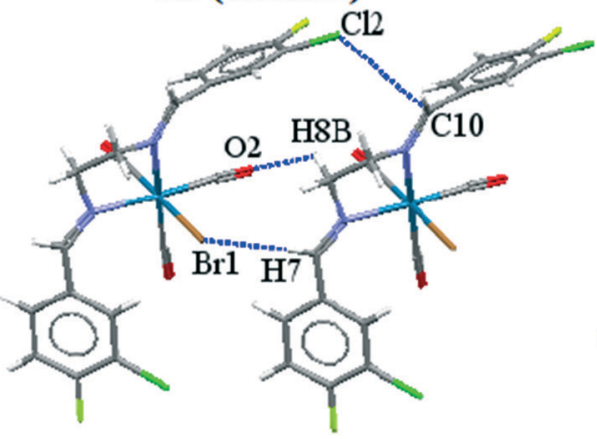

C3 (dimer4)

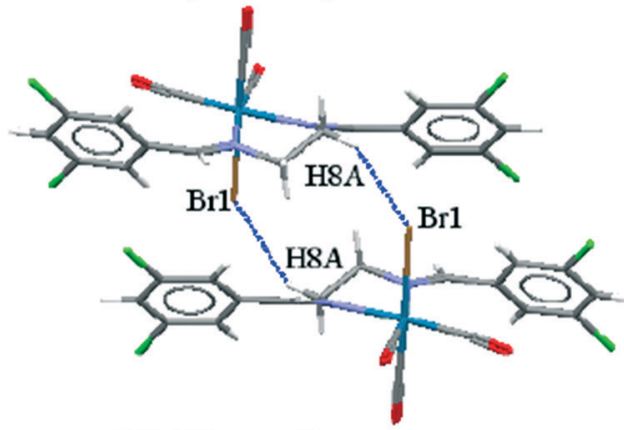

C5 (dimer6)

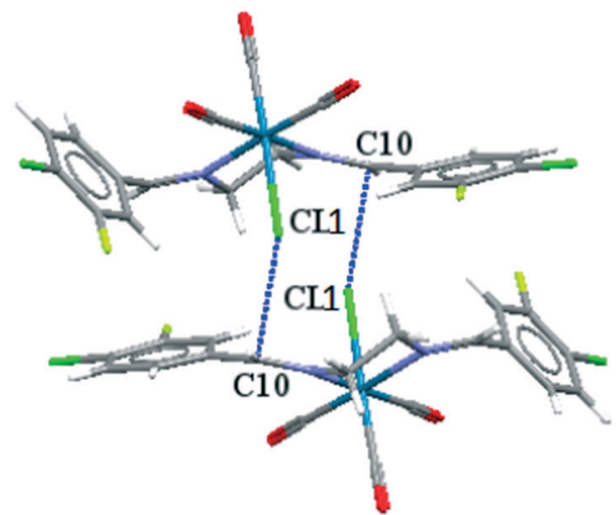

C8 (dimer4)

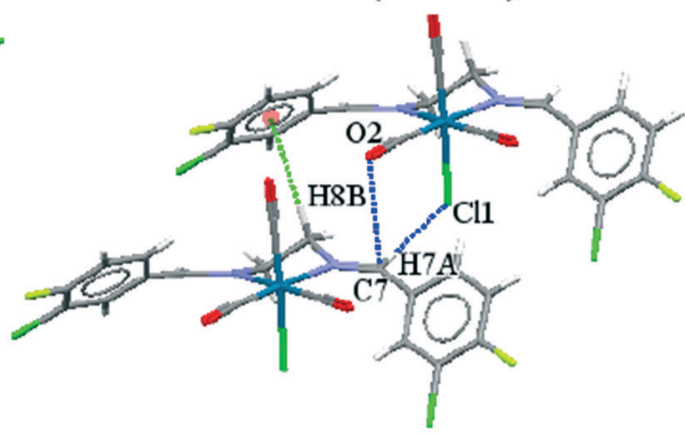

C4 (dimer2)

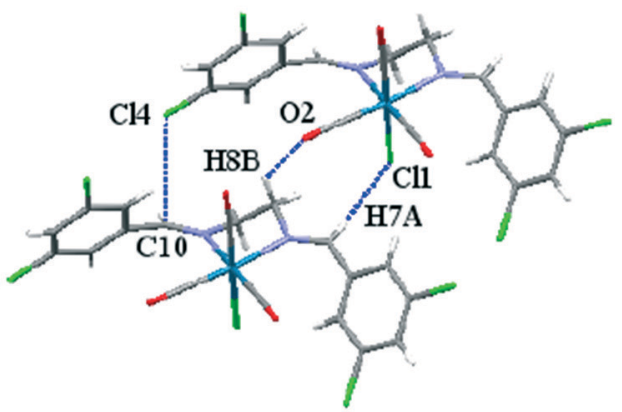

C6 (dimer3)

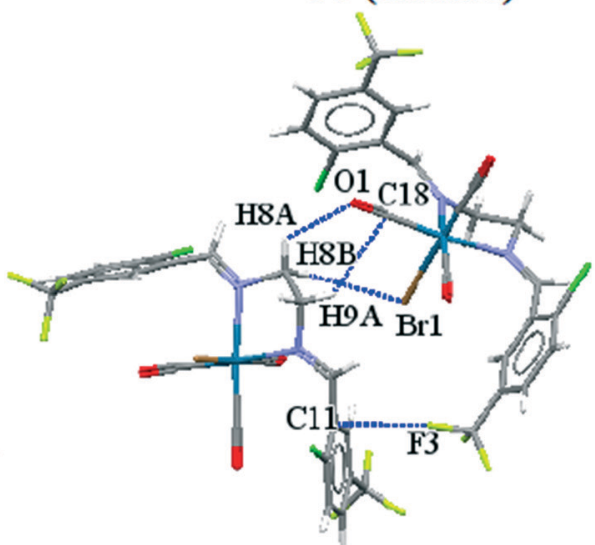

C10 (dimer3)

Fig. 12 Some of the crystallographic dimers used for intermolecular interactions energy calculation.

$-0.03<\rho \times \operatorname{sign}\left(\lambda_{2}\right)<+0.03$ [colour scale: attractive (blue) $\rightarrow$ repulsive (red)] and the corresponding plots of $\rho \times \operatorname{sign}\left(\lambda_{2}\right) v s$. reduced density gradient highlighting the halogen bonding were shown in the ESI $\dagger$ (Fig. S35a-o).

\section{Hirshfeld surface studies}

In order to obtain a deeper understanding of the intermolecular interactions in the molecular packing of the 
Table 5 QTAIM parameters (in a.u.) at the BCP of the intermolecular interactions

\begin{tabular}{lll}
\hline Interaction & $\rho_{\mathrm{b}}$ & $\nabla^{2} \rho_{\mathrm{b}}$ \\
\hline $\mathrm{Cl}^{1} \cdots \mathrm{H} 10 \mathrm{~A}$ (dimer4 in C2) & 0.011 & 0.030 \\
$\mathrm{Br}^{\cdots} \cdots \mathrm{H} 8 \mathrm{~A}$ (dimer6 in C5) & 0.010 & 0.024 \\
$\mathrm{Cl}^{1} \cdots \mathrm{C} 10$ (dimer4 in C8) & 0.008 & 0.032 \\
$\mathrm{~F} 1 \cdots \mathrm{H} 7$ (dimer3 in C9) & 0.008 & 0.036
\end{tabular}

complexes, an analysis of their Hirshfeld surfaces was conducted. The Hirshfeld contact surfaces as $d_{\text {norm }}$ for complexes C1-C10 and their 2D fingerprint plots are shown in Fig. S36 and S37, $\uparrow$ respectively. The information presented in Table 3 is shown pictorially in the Hirshfeld surface plots (Fig. S36†) to aid the analysis of the intermolecular interactions. According to the Hirshfeld surface analysis, the intermolecular $\mathrm{H}^{\cdots} \mathrm{H}$ contacts, i.e. dispersive interactions, contribute $13 \%$ of the total number of contacts in the crystal packing of $\mathbf{C 1}$. The shortest $\mathrm{H} \cdots \mathrm{H}$ contact appears as broad spikes at $d_{\mathrm{e}}+d_{\mathrm{i}} \approx 2.2 \AA$ in the fingerprint plot. The $\mathrm{Cl} \cdots \mathrm{H}$ contact makes a $21 \%$ contribution in the fingerprint plot but the shortest contact between $\mathrm{Cl}$ and $\mathrm{H}$ is longer than their sum of the van der Waals radii, therefore, it is not the main intermolecular short contact in the crystal packing of C1. The structure of $\mathbf{C} 1$ is dominated by $\mathrm{Br} \cdots \mathrm{H}(9.3 \%)$ and $\mathrm{O} \cdots \mathrm{H}$ $(8 \%)$ contacts. The $\mathrm{Br} \cdots \mathrm{H}$ contact in the fingerprint plot is shown as wings having sharp spikes with the shortest $d_{\mathrm{e}}+d_{\mathrm{i}}$ $\approx 2.8 \AA$. The shortest $\mathrm{O} \cdots \mathrm{H}$ contacts are appeared in the fingerprint plot as characteristic sharp spikes at $d_{\mathrm{e}}+d_{\mathrm{i}} \approx 2.4 \AA$. In a similar manner to $\mathbf{C} 1$, the main contribution to the intermolecular interactions of $\mathbf{C} 2$ in the fingerprint plot arises from $\mathrm{O} \cdots \mathrm{H}$ contact and metal-bound halogen $(\mathrm{Cl})$ with 24.3 and $21.3 \%$ in the crystal packing. Both contacts feature characteristic sharp spikes at $d_{\mathrm{e}}+d_{\mathrm{i}} \approx 2.2 \AA$. The intermolecular $\mathrm{H}^{\cdots} \mathrm{H}$ contacts contribute almost $12 \%$ of the total number of contacts in the crystal packing. Further inspection of other intermolecular contacts in the structure of $\mathbf{C} 2$ re-

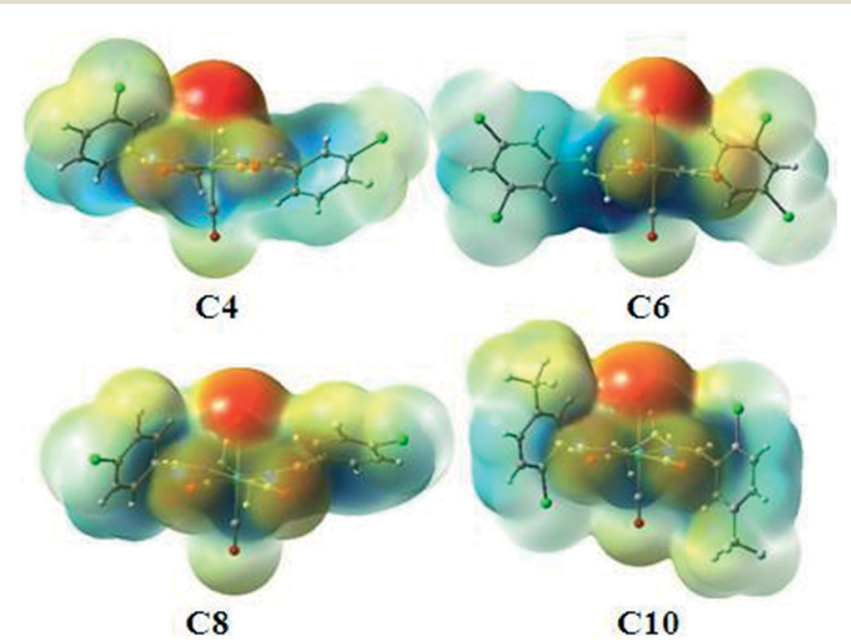

Fig. 13 The maps of electrostatic potential of C4, C6, C8 and C10 [isovalue at -0.045 (red) and 0.045 (blue)]. vealed a portion of $\mathrm{C} \cdots \mathrm{C}, \mathrm{C} \cdots \mathrm{O}, \mathrm{Cl} \cdots \mathrm{O}$ and $\mathrm{C} \cdots \mathrm{Cl}$ contacts with less than $5 \%$ contribution. By introducing $\mathrm{Cl}$ and $\mathrm{F}$ in 3 and 4 positions of the arene rings of $\mathrm{C} 4$, again $\mathrm{H} \cdots \mathrm{O}$ and $\mathrm{H} \cdots \mathrm{Br}$ are dominant interactions in the crystal packing as it is shown in the fingerprint plot with 21.1 and $7.1 \%$ of the total number of contacts, respectively. They are appeared as sharp spikes at $d_{\mathrm{e}}+d_{\mathrm{i}} \approx 2.2 \AA$ for $\mathrm{H} \cdots \mathrm{O}$ and $2.75 \AA$ for $\mathrm{H} \cdots \mathrm{Br}$. The fingerprint plot of $\mathbf{C} 3$ features a weak $\mathrm{Cl} \cdots \mathrm{F}$ interaction as sharp spikes at $d_{\mathrm{e}}+d_{\mathrm{i}} \approx 3.0 \AA$ but with negligible contribution $(4.3 \%)$ of the total number of contacts. In the fingerprint plot of $\mathbf{C} 4$ characteristic sharp spikes at $d_{\mathrm{e}}+d_{\mathrm{i}} \approx$ $2.5 \AA$, arise from the interaction of the metal coordinated chloride with hydrogen $\left(\mathrm{H}^{\cdots} \mathrm{Cl}\right)$, having $24.5 \%$ of the total number of contacts in the crystal packing. The main contribution in the fingerprint plot of $\mathbf{C} 5$ arises from $\mathrm{H} \cdots \mathrm{O}, \mathrm{H} \cdots \mathrm{Br}$ and $\mathrm{H}^{\cdots} \mathrm{Cl}$ interactions with overall $18.4,9.6$ and $19.5 \%$ contribution to the surface in the crystal packing. They appear as sharp spikes at $d_{\mathrm{e}}+d_{\mathrm{i}} \approx 2.4 \AA$ for $\mathrm{H} \cdots \mathrm{O}, \approx 2.80 \AA$ for $\mathrm{H} \cdots \mathrm{Br}$ and at $\approx 2.70 \AA$ for $\mathrm{H} \cdots \mathrm{Cl}$. In the crystal packing of $\mathrm{C} 5$ the metal-coordinated halogen $(\mathrm{Br})$ and substituted $\mathrm{Cl} 2$ atoms contribute to $\mathrm{H} \cdots \mathrm{Br}$ and $\mathrm{H} \cdots \mathrm{Cl}$ interactions. The fingerprint plot of $\mathrm{C6}$ corresponds to $\mathrm{H} \cdots \mathrm{Cl}$ and $\mathrm{H} \cdots \mathrm{O}$ contacts with a pair of superimposed sharp spikes with an overall $28 \%$ and $19 \%$ contribution to the surface, respectively. The spikes related to $\mathrm{H} \cdots \mathrm{Cl}$ and $\mathrm{H} \cdots \mathrm{O}$ is located at $d_{\mathrm{e}}+d_{\mathrm{i}} \approx 2.6 \AA$ and $2.31 \AA$, respectively. The weak $\mathrm{Cl} \cdots \mathrm{Cl}$ contact less than the sum of the van der Waals radii of $\mathrm{Cl}$ was contributed to the Hirshfeld surface $(7 \%)$ of $\mathbf{C 6}$ at $d_{\mathrm{e}}+d_{\mathrm{i}} \approx 3.4 \AA$. In these three pairs (C1-C6) it can be seen that by changing the metalcoordinated halogen the fingerprint plot change significantly. The most significant intermolecular interaction in the crystal packing of $\mathrm{C} 7$ is non-classic $\mathrm{C}-\mathrm{H} \cdots \mathrm{O}$ interactions which are appeared by superimposed sharp spikes with an overall $17.6 \%$ contribution to the surface at $d_{\mathrm{e}}+d_{\mathrm{i}} \approx 2.4 \AA$. The fingerprint plot of $\mathbf{C 8}$ is favored by the intermolecular $\mathrm{H} \cdots \mathrm{Cl}$, $\mathrm{H} \cdots \mathrm{O}$ and $\mathrm{H} \cdots \mathrm{F}$ contacts with an overall $21 \%, 18 \%$ and $14 \%$ contribution to the surface. The $\mathrm{H} \cdots \mathrm{Cl}$ and $\mathrm{H} \cdots \mathrm{O}$ interactions in the fingerprint plot appeared as wing at $d_{\mathrm{e}}+d_{\mathrm{i}} \approx 2.9$ $\AA$ and $2.6 \AA$, respectively. The $\mathrm{H} \cdots \mathrm{F}$ contacts are shown as superimposed sharp and long spikes at $d_{\mathrm{e}}+d_{\mathrm{i}} \approx 2.2 \AA$ in the fingerprint plot. The $\mathrm{H} \cdots \mathrm{F}$ contacts contribution in the structure of $\mathbf{C 8}$ is the most significant comparing to the rest of the structures. The most significant intermolecular contact in the fingerprint plot of $\mathbf{C 9}$ is $\mathrm{H} \cdots \mathrm{F}$ and $\mathrm{H} \cdots \mathrm{Br}$ with an overall 27.4 and $7.4 \%$ contribution to the surface which appear at $d_{\mathrm{e}}+d_{\mathrm{i}}$ $\approx 2.36 \AA$ and $2.8 \AA$, respectively. The fingerprint plot of $\mathbf{C 1 0}$ features the presence of short $\mathrm{O} \cdots \mathrm{H}$ and $\mathrm{Cl} \cdots \mathrm{O}$ contacts with overall $10.7 \%$ and $7 \%$ contribution to the Hirshfeld surface appearing at $d_{\mathrm{e}}+d_{\mathrm{i}} \approx 2.5 \AA$ and $3.0 \AA$, respectively. The sharp superimposed spikes at $3.0 \AA$ indicate the significant short $\mathrm{Cl} \cdots \mathrm{O}$ contact. It is noteworthy to mention that in $\mathbf{C 1}-\mathbf{C 6}$ and C9, the metal-coordinated halogen with nucleophilic character, as shown in the electrostatic maps (MEP, Fig. S17-S26 $\dagger$ ), is more effective in the intermolecular contacts, directing the crystal packing, comparing to the carbon-substituted halogen atoms. 

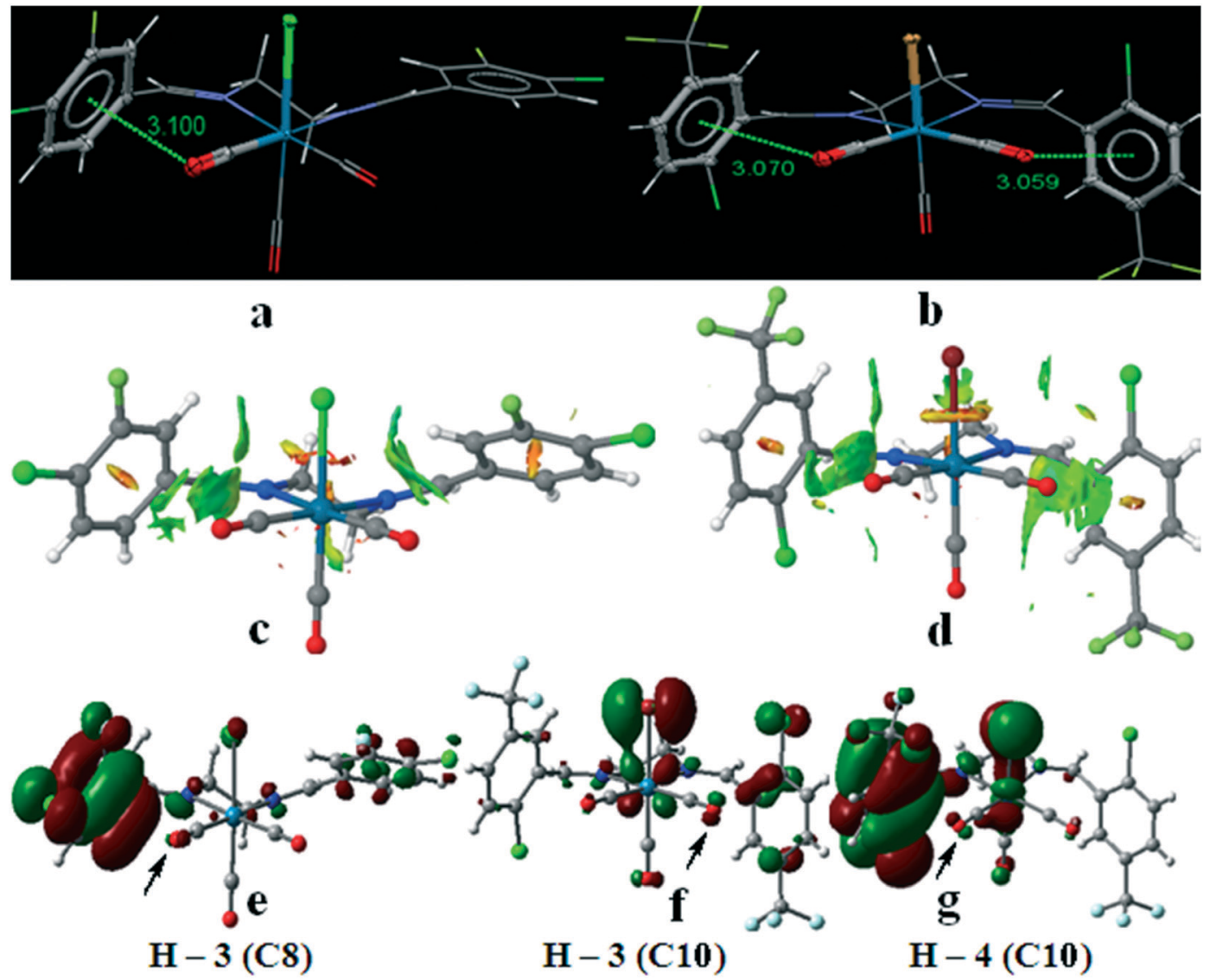

Fig. 14 The $\mathrm{C} \equiv \mathrm{O}$ (lone-pair) $\cdots \pi$ interactions (top, a and b), NCIPLOT (middle, $\mathrm{c}$ and $\mathrm{d}$ ) and the molecular orbitals (bottom, e-g) of C8 and C10, respectively. The arrows in e-g show the contribution of the lone pair of the oxygen atom.

\section{Conclusions}

In conclusion, nine new rhenium(I) tricarbonyl complexes bearing halogen-substituted NN-donor ligands were synthesized and structurally characterized by X-ray diffraction, FTIR, ${ }^{1} \mathrm{H}$-NMR and elemental analyses. The detailed analysis of the crystal packing along with their interaction energies of the crystallographically generated dimers connected by the related intermolecular interactions confirmed that the metalbound halogen $(\mathrm{Re}-\mathrm{X})$, is more effective than organic halogen $(\mathrm{C}-\mathrm{X})$ in directing the crystal packing. This evaluation was also confirmed using molecular electrostatic potential (MEP) surface calculations at metal-bond halogen which was also

Table 6 BP86-D3/def2TZVP calculated percentage composition of selected molecular orbitals of C8 and C10 based on their fragment orbitals

\begin{tabular}{lllllll}
\hline Complex & $\mathrm{Re} 1$ & $\mathrm{X}$ & $\mathrm{CO}_{\mathrm{ax}}$ & $\mathrm{CO}_{\text {eq1 }}$ & $\mathrm{CO}_{\text {eq2 }}$ & Ligand \\
\hline $\mathrm{C} 8$ & & $\mathrm{X}=\mathrm{Cl}$ & & & & \\
$\mathrm{H}-3$ & 2 & 1.9 & 0.1 & 0.4 & 1.3 & 94.2 \\
$\mathrm{C} 10$ & & $\mathrm{X}=\mathrm{Br}$ & & & & \\
$\mathrm{H}-3$ & 14.4 & 33.8 & 2.4 & 2.9 & 1.2 & 40.3 \\
$\mathrm{H}-4$ & 3.3 & 6.4 & 0.9 & 0.3 & 0.7 & 88.4
\end{tabular}

$\mathrm{ax}=$ axial, eq1 $=$ right hand side equatorial to $\mathrm{X}$, eq2 = left hand side equatorial to $\mathrm{X}$, Ligand $=\mathrm{NN}$-ligand. confirmed by the Hirshfeld surface analyses. A rare intramolecular $\mathrm{M}-\mathrm{C} \equiv \mathrm{O}$ (lone-pair) $\cdots \pi$ interactions were found in two complexes (C8 and C10) with short intramolecular metalbound carbonyl and arene ring which were confirmed by non-covalent interaction index (NCI) and molecular orbital calculations.

\section{Conflicts of interest}

There are no conflicts to declare.

\section{Acknowledgements}

RK is thankful to Sharif University of Technology research Council for the research facility and to Bath University for a visiting lectureship. PRR is grateful to the Engineering and Physical Sciences Research Council (EPSRC) for continued funding (EP/K004956/1).

\section{References}

1 (a) H. A. Sparkes, P. R. Raithby, E. Clot, G. P. Shields, J. A. Chisholm and F. H. Allen, CrystEngComm, 2006, 8, 563-570; (b) F. H. Allen, C. A. Baalham, J. P. M. Lommerse and P. R. Raithby, Acta Crystallogr., Sect. B: Struct. Sci., 1998, 54, 320-329. 
2 J. M. Lehn, Science, 1985, 227, 849.

3 C. B. Aakeröy, N. R. Champness and C. Janiak, CrystEngComm, 2010, 12, 22-43.

4 C. B. Aakeröy, A. Rajbanshi, Z. J. Li and J. Desper, CrystEngComm, 2010, 12, 4231-4239.

5 L. M. Salonen, M. Ellermann and F. Diederich, Angew. Chem., Int. Ed., 2011, 50, 4808-4842.

6 J. W. Steed and J. L. Atwood, Supramolecular chemistry, Wiley, Chichester, 2000.

7 G. R. Desiraju, Perspectives in Supramolecular Chemistry, John Wiley \& Sons, Chichester, UK, 1996, vol. 2.

8 C. C. Robertson, J. S. Wright, E. J. Carrington, R. N. Perutz, C. A. Hunter and L. Brammer, Chem. Sci., 2017, 8(8), 5392-5398.

9 (a) A. S. Mahadevi and G. N. Sastry, Chem. Rev., 2016, 116, 2775-2825; (b) Z. Han, Y. Zhao, J. Peng, A. Tian, Q. Liu, J. Ma, E. Wanga and N. Hu, CrystEngComm, 2005, 7(63), 380-387.

10 L. C. Gilday, S. W. Robinson, T. A. Barendt, M. J. Langton, B. R. Mullaney and P. D. Beer, Chem. Rev., 2015, 115, 7118-7195.

11 L. Maugeri, J. Asencio-Hernandez, T. Lebl, D. B. Cordes, A. M. Z. Slawin, M.-A. Delsuc and D. Philp, Chem. Sci., 2016, 7, 6422-6428.

12 L. Brammer, G. M. Espallargas and H. Adams, CrystEngComm, 2003, 5(60), 343-345.

13 T. Brinck, J. S. Murray and P. Politzer, Int. J. Quantum Chem., 1992, 44, 57-64.

14 T. Clark, M. Hennemann, J. S. Murray and P. Politzer, J. Mol. Model., 2007, 13, 291-296.

15 M. Hennemann, J. S. Murray, K. E. Riley, P. Politzer and T. Clark, J. Mol. Model., 2012, 18, 2461-2469.

16 M. Palusiak, J. Mol. Struct., 2010, 945, 89-92.

17 K. E. Riley and P. Hobza, J. Chem. Theory Comput., 2008, 4, 232-242.

18 A. J. Stone, J. Am. Chem. Soc., 2013, 135, 7005-7009.

19 P. Metrangolo and G. Resnati, Cryst. Growth Des., 2012, 12, 5835-5838.

20 L. Brammer, E. A. Bruton and P. Sherwood, Cryst. Growth Des., 2001, 1(4), 277-290.

21 G. M. Espallargas, F. Zordan, L. A. Marin, H. Adams, K. Shankland, J. van de Streek and L. Brammer, Chem. - Eur. J., 2009, 15, 7554-7568.

22 (a) Halogen Bonding: Fundamentals and Applications, ed. G. Metrangolo and G. Resnati, Springer, Berlin, 2008; $(b)$ L. Meazza, J. Martí-Rujas, G. Terraneo, C. Castiglioni, A. Milani, T. Pilati, P. Metrangolo and G. Resnati, CrystEngComm, 2011, 13, 4427-4435.

23 J. Martí-Rujas, L. Meazza, G. Keat Lim, L. Terraneo, T. Pilati, K. D. M. Harris, P. Metrangolo and G. Resnati, Angew. Chem., Int. Ed., 2013, 52, 13444-13448.

24 L. Brammer, G. M. Espallargas and S. Libri, CrystEngComm, 2008, 10, 1712-1727.

25 L. Brammer, Faraday Discuss., 2017, 203, 485-507.

26 F. Zordan, G. M. Espallargas and L. Brammer, CrystEngComm, 2006, 8, 425-431.
27 S. Haddad, F. Awwadi and R. D. Willet, Cryst. Growth Des., 2003, 3, 501.

28 (a) J. C. Calabrese, D. B. Jordan, A. Boodhoo, S. Sariaslani and T. Vannelli, Biochemistry, 2004, 43, 11403-11416; (b) E. J. Stollar, J. L. Gelpi, S. Velankar, A. Golovin, M. Orozco and B. F. Luisi, Proteins, 2004, 57, 1-8; (c) T. J. Mooibroek, P. Gamez and J. Reedijk, CrystEngComm, 2008, 10, 1501-1515; (d) M. Eali and S. Sarkhel, Acc. Chem. Res., 2007, 40, 197-205.

29 (a) J. Zukerman-Schpector, I. Haiduc and E. R. T. Tiekink, Chem. Commun., 2011, 47, 12682-12684; (b) J. ZukermanSchpector, I. Haidu and E. R. T. Tiekink, Adv. Organomet. Chem., 2012, 60, 49-92; (c) C.-Q. Wan, X.-D. Chen and T. C. W. Mak, CrystEngComm, 2008, 10, 475-478.

30 C. Murcia-García, A. Bauzá, G. Schnakenburg, A. Frontera and R. Streubel, CrystEngComm, 2015, 17, 1769-1772.

31 Y. S. Rosokha, S. V. Lindeman, S. V. Rosokha and J. K. Kochi, Angew. Chem., Int. Ed., 2004, 43, 4650-4652.

32 J. Echeverria, Chem. Commun., 2018, 54, 3061-3064.

33 M. T. Doppert, H. van Overeem and T. J. Mooibroek, Chem. Commun., 2018, 54, 12049-12052.

34 P. Murray-Rust, H. B. Burgi and J. D. Dunitz, J. Am. Chem. Soc., 1975, 97, 921-928.

35 (a) J. R. Shaw and R. H. Schmehl, J. Am. Chem. Soc., 1991, 113, 389-394; (b) S. Ranjan, S.-Y. Lin, K.-C. Hwang, Y. Chi, W.-L. Ching, C.-S. Liu, Y.-T. Tao, C.-H. Chien, S.-M. Peng and G.-H. Lee, Inorg. Chem., 2003, 42, 1248-1255; (c) Z. Si, J. Li, B. Li, F. Zhao, S. Liu and W. Li, Inorg. Chem., 2007, 46, 6155-6163.

36 (a) Y. Kou, Y. Nabetani, D. Masui, T. Shimada, S. Takagi, H. Tachibana and H. Inoue, J. Am. Chem. Soc., 2014, 136, 6021-6030; (b) J. Shakeri, H. Farrokhpour, H. Hadadzadeh and M. Joshaghani, RSC Adv., 2015, 5, 41125-41134; (c) L. E. Hatcher, CrystEngComm, 2018, 20, 5990-5997.

37 (a) J. C. Calabrese, D. B. Jordan, A. Boodhoo, S. Sariaslani and T. Vannelli, Biochemistry, 2004, 43, 11403-11416; (b) E. J. Stollar, J. L. Gelpi, S. Velankar, A. Golovin, M. Orozco and B. F. Luisi, Proteins, 2004, 57, 1-8; (c) M. Eali and S. Sarkhel, Acc. Chem. Res., 2007, 40, 197-205; (d) T. J. Mooibroek, P. Gamez and J. Reedijk, CrystEngComm, 2008, 10, 1501-1515.

38 H.-K. Fun and R. Kia, Acta Crystallogr., Sect. E: Struct. Rep. Online, 2008, 64, 01916.

39 H.-K. Fun and R. Kia, Acta Crystallogr., Sect. E: Struct. Rep. Online, 2008, 64, 02131.

40 H.-K. Fun and R. Kia, Acta Crystallogr., Sect. E: Struct. Rep. Online, 2008, 64, 01941.

41 H.-K. Fun and R. Kia, Acta Crystallogr., Sect. E: Struct. Rep. Online, 2008, 64, 02169.

42 H.-K. Fun and R. Kia, Acta Crystallogr., Sect. E: Struct. Rep. Online, 2008, 64, 01722.

43 R. Kia and H.-K. Fun, Acta Crystallogr., Sect. E: Struct. Rep. Online, 2008, 65, m192.

44 J. M. Villegas, S. R. Stoyanov, W. Huang and D. P. Rillema, Dalton Trans., 2005, 1042-1051.

45 R. C. Clark and J. S. Reid, Acta Crystallogr., Sect. A: Found. Crystallogr., 1995, 64, 887-897. 
46 SuperNova Eos S2 System: Empirical absorption correction, 2011, CrysAlis-Software package, Oxford Diffraction Ltd.

47 Z. Otwinowski and W. Minor, Methods Enzymol., 1997, 276, 307-326.

48 O. V. Dolomanov, L. J. Bourhis, R. J. Gildea, J. A. K. Howard and H. Puschmann, J. Appl. Crystallogr., 2009, 42, 339-341 and Agilent (2012). AutoChem 2.0, in conjunction with OLEX2. Agilent Technologies UK Ltd, Yarnton, Oxfordshire, England.

49 G. M. Sheldrick, Acta Crystallogr., Sect. A: Found. Crystallogr., 2008, 64, 112-122.

50 A. L. Spek, Acta Crystallogr., Sect. D: Biol. Crystallogr., 2009, 65, 148-155.

51 M. J. Frisch, G. W. Trucks, H. B. Schlegel, G. E. Scuseria, M. A. Robb, J. R. Cheeseman, G. Scalmani, V. Barone, B. Mennucci, G. A. Petersson, H. Nakatsuji, M. Caricato, X. Li, H. P. Hratchian, A. F. Izmaylov, J. Bloino, G. Zheng and D. J. Sonnenb, Gaussian 09, Revision A.02.

52 A. Bauzá, A. Terrón, M. Barceló-Oliver, A. García-Raso and A. Frontera, Inorg. Chim. Acta, 2016, 452, 244-250.

53 D. Sadhukhan, M. Maiti, G. Pilet, A. Bauzá, A. Frontera and S. Mitra, Eur. J. Inorg. Chem., 2015, 11, 1958-1972.

54 M. Mirzaei, H. Eshtiagh-Hosseini, Z. Bolouri, Z. Rahmati, A. Esmaeilzadeh, A. Hassanpoor, A. Bauza, P. Ballester, M.
Barceló-Oliver, J. T. Mague, B. Notash and A. Frontera, Cryst. Growth Des., 2015, 15, 1351-1361.

55 P. Chakraborty, S. Purkait, S. Mondal, A. Bauzá, A. Frontera, C. Massera and D. Das, CrystEngComm, 2015, 17, 4680-4690.

56 S. F. Boys and F. Bernardi, Mol. Phys., 1970, 19, 553-566.

57 F. Weigend and R. Ahlrichs, Phys. Chem. Chem. Phys., 2005, 7, 3297-3305.

58 (a) NCIplot, version 3.0., Department of Chemistry, Duke University, USA, 2011, http://www.chem.duke.edu/ yang/ Software/softwareNCI.html; (b) E. R. Johnson, S. Keinan, S. P. Mori-Sánchez, J. Contreras-García, A. J. Cohen and W. Yang, J. Am. Chem. Soc., 2010, 132, 6498-6506; (c) J. Contreras-García, E. R. Johnson, S. Keinan, R. Chaudret, J. P. Piquemal, D. N. Beratan and W. Yang, J. Chem. Theory Comput., 2011, 7, 625-632.

59 F. Biegler-König and J. J. Schönbohm, Comput. Chem., 2002, 23(15), 1489-1494.

60 (a) J. J. McKinnon, D. Jayatilaka and M. A. Spackman, Chem. Commun., 2007, 3814-3816; (b) M. A. Spackman and J. J. McKinnon, CrystEngComm, 2002, 4, 378-392.

61 S. K. Wolff, D. J. Grimwood, J. J. McKinnon, M. J. Turner, D. Jayatilaka and M. A. Spackman, CrystalExplorer, version 3.0, University of Western Australia, Crawley, Australia, 2012. 